\title{
Thermal Responses to Antarctic Ice Shelf Melt in an Eddy-Rich Global Ocean-Sea Ice Model
}

\author{
Ruth Moorman, Adele K. Morrison, And Andrew McC. HogG \\ Research School of Earth Sciences, and ARC Centre of Excellence for Climate Extremes, Australian National University, \\ Canberra, Australian Capital Territory, Australia
}

(Manuscript received 15 November 2019, in final form 21 April 2020)

\begin{abstract}
The response of near-Antarctic waters to freshening by increased glacial melt is investigated using a highresolution $\left(0.1^{\circ}\right)$ global ocean-sea ice model with realistic Antarctic water-mass properties. Two meltwater perturbation experiments are conducted where the ocean model is forced with constant elevated glacial melt rates of 1.5 and 2.8 times the control rate. Within 10 years of the onset of enhanced meltwater forcing, the generation of Antarctic Bottom Water from Dense Shelf Water ceases, as shelf waters become increasingly buoyant. Increased ocean stratification triggers subsurface warming in Dense Shelf Water source regions, suggesting a localized positive feedback to melt. In a parallel response, meltwater forcing enhances the subsurface lateral density gradients of the Antarctic Slope Front that modulate the transport of warm Circumpolar Deep Water across the continental slope toward ice shelf grounding lines. Consequently, coastal freshening acts to isolate the Antarctic Ice Sheet from open ocean heat, suggesting a cooling response to melt that counteracts warming associated with stratification. Further, these strengthening density gradients accelerate westward geostrophic currents along the coast and shelf break, homogenizing shelf waters and amplifying remote feedbacks. The net effect on the continental shelf is transient warming, followed by cooling in both experiments; however, this signal is the aggregate of a complex pattern of regional warming and cooling responses. These results suggest coastal freshening by meltwater may alter the thermal forcing of the Antarctic ice sheet in ways that both accelerate and inhibit ice shelf melt at different locations along the Antarctic coastline.
\end{abstract}

\section{Introduction}

The Antarctic Ice Sheet poses the largest potential mass contribution to global sea level rise, with an estimated $58 \mathrm{~m}$ of sea level equivalent contained in land ice on the continent (Fretwell et al. 2013; Morlighem et al. 2019). The melting of Antarctic land ice has accelerated in recent decades, with losses from the marine terminating glaciers of the West Antarctic Ice Sheet driving the trend (Paolo et al. 2015; Shepherd et al. 2018). In addition to driving sea level rise, the observed acceleration of ice loss from Antarctica implies an increasing freshwater flux into Antarctic coastal seas. The effects of this buoyancy forcing on Antarctic ocean circulation are poorly constrained by observations and models, due to the spatial and temporal scarcity of direct observations near the Antarctic coast (Smith et al. 2019) and the high resolution required to simulate small-scale processes dictating circulation on the Antarctic continental shelf

\footnotetext{
Corresponding author: Ruth Moorman, ruthmoorman1@gmail.com
}

and margin in ocean models (Stewart and Thompson 2015). Understanding how near-Antarctic waters respond to freshwater forcing is important for constraining future rates of ice shelf melt and sea level rise.

A possible dynamical response to increasing freshwater input, suggested by observed deep ocean heat and salinity trends (Jacobs and Giulivi 2010; Purkey and Johnson 2010, 2012, 2013) and previous simulation studies (e.g., Aiken and England 2008; Fogwill et al. 2015; Kirkman and Bitz 2011; Menviel et al. 2010; Morrison et al. 2015; Snow et al. 2016; Stouffer et al. 2007; Lago and England 2019), is that coastal freshening will disrupt the production of Antarctic Bottom Water $(\mathrm{AABW})$, a dense water mass that fills the majority of the abyssal oceans (Johnson 2008). AABW is sourced from reservoirs of cold and saline dense waters that pool on the Antarctic continental shelf following substantial surface buoyancy losses associated with sea ice production in polynyas near the Antarctic coast (Orsi et al. 1999). These downwelling coastal waters, referred to as Dense Shelf Water (DSW), are the precursor to AABW. 
DSW spills over the shelf break in localized plumes that cascade down the continental slope to the abyssal ocean where they flow northward as AABW (Jacobs 2004). DSW generation is known to be sensitive to coastal freshening (Snow et al. 2016; Silvano et al. 2018) due to its dependence on surface water densification by brine rejection near the Antarctic coast. However, it is less clear how a reduction in DSW production would impact the heat budget of the Antarctic continental shelf and ice sheet.

Where DSW breaches the continental shelf margin at overflow sites, it interacts with a relatively warm, saline water mass occupying the middepths north of the shelf break, Circumpolar Deep Water (CDW). Poleward CDW transport is considered to be the dominant heat flux driving basal melt beneath Antarctic ice shelves (Stewart et al. 2018), and its presence near ice shelf grounding lines has been linked to high melt rates in West Antarctica (Jenkins et al. 2018). Around most of Antarctica, the steeply sloping isopycnals of the Antarctic Slope Front (ASF) provide a natural barrier inhibiting the transport of warm $\mathrm{CDW}$, and its intrinsic melt potential, to ice shelf grounding lines (Thompson et al. 2018). Ekman downwelling velocities induced by persistent coastal easterly winds depress isopycnals toward the coast (Spence et al. 2014) and, in some regions, this isopycnal tilting is sufficiently steep that density surfaces containing warm CDW incrop on the continental slope. This isopycnal incropping prevents CDW from accessing the continental shelf except where modified by diapycnal mixing, and thus limits the transport of open ocean heat to the Antarctic Ice Sheet (Thompson et al. 2018). No such frontal barrier to shoreward CDW transport exists at DSW overflow sites, which necessarily maintain isopycnal connections between offshore CDW and shelf waters, and may even actively drive shoreward CDW transport (Stewart and Thompson 2016; Morrison et al. 2020). Nor is a strong ASF found in the Amundsen and Bellingshausen Seas of West Antarctica, where CDW floods the continental shelf and drives high basal melt rates (e.g., Cook et al. 2016; Jenkins et al. 2016, 2018; Moffat and Meredith 2018; Schmidtko et al. 2014). Both DSW formation regions and the Amundsen and Bellingshausen Seas present potential hotspots for cross-slope heat exchange by permitting along isopycnal CDW transport to the shelf. Meltwater-induced density shifts near the Antarctic coast may modify these cross-slope isopycnal structures and alter the pathways by which open ocean heat accesses the continental shelf.

Prior simulation studies have found that coastal freshening triggers strong subsurface warming trends around Antarctica, suggesting a positive feedback whereby coastal freshening by meltwater accelerates further melt (Menviel et al. 2010; Fogwill et al. 2015; Bronselaer et al. 2018; Schloesser et al. 2019; Golledge et al. 2019). However, studies that report this feedback utilize relatively coarse $\left(>1^{\circ}\right.$ grid) ocean models that do not resolve features such as the narrow ASF, localized DSW overflows, or eddydriven shoreward CDW transports that contribute to the Antarctic continental shelf heat budget. As such, while previous Antarctic meltwater perturbation experiments using global models offer useful insights into the sensitivity of large-scale circulation systems and open ocean water-mass characteristics to freshwater forcing, they are ill equipped to diagnose feedbacks to the Antarctic continental shelf or Antarctic Ice Sheet. Using a higher-resolution $\left(0.25^{\circ}\right.$ grid $)$ ocean sector model with realistic DSW formation and export pathways, Snow et al. (2016) found that meltwater-induced Antarctic ocean warming is confined to the deep ocean, and that continental shelf waters cool in response to freshwater forcing, suggesting a negative feedback to melt. However, the $0.25^{\circ}$ grid used by Snow et al. (2016) is insufficient to resolve eddy driven cross-slope heat transport either within or outside DSW overflow sites. Previous regional (St-Laurent et al. 2013; Graham et al. 2016) and idealized (Stewart and Thompson 2015) modeling studies have suggested a horizontal grid scale of $\sim 1 \mathrm{~km}$ (nominally $\sim 1 / 48^{\circ}$ ) is required to fully resolve eddy-driven transports of CDW and DSW across the Antarctic continental shelf margin, although substantial improvements in the representation of crossslope exchange have been achieved at horizontal grid scales $\leq 5 \mathrm{~km}$ (Nakayama et al. 2014) (nominally $\sim 1 / 10^{\circ}$ ). Furthermore, Snow et al.'s (2016) use of a sector model neglects remote feedbacks and circum-Antarctic variability. Recent improvements in high-resolution global ocean-sea ice modeling provide the opportunity to interrogate these feedbacks in simulations that represent many observed processes operating at the continental shelf margin and span the full circumpolar domain, although fully resolving near-Antarctic mesoscale eddy activity in circumpolar models remains computationally challenging.

In this study, we use a high-resolution $\left(0.1^{\circ}\right.$ grid $)$, global, coupled ocean-sea ice model with a realistic representation of near-Antarctic water masses to investigate the response of Antarctic ocean circulation to increased glacial melt rates. The central aim is to identify possible feedback mechanisms whereby the freshening of Antarctic coastal oceans by increasing glacial meltwater fluxes may increase or decrease the thermal forcing of ice shelves, and thus accelerate or limit future ice shelf melt. To this end, we conduct two enhanced meltwater experiments, assessing shifts in the Antarctic shelf water properties and the exchange of heat and 
water masses (i.e., DSW and CDW) across the continental shelf break triggered by increasing freshwater inputs.

\section{Model and methods}

\section{a. The ACCESS-OM2-01 ocean-sea ice model}

The principal tool of this study is ACCESS-OM2-01 [for details, see Kiss et al. (2019)], a $0.1^{\circ}$ global oceansea ice model comprising the MOM5.1 ocean model (Griffies 2012) coupled to the CICE5.1.2 sea ice model (Hunke et al. 2015), with atmospheric forcing represented by the JRA55-do v1.3 surface forcing product (Tsujino et al.2018). In this section, we provide details of the model configuration and spinup protocol, and justify its suitability to the study of ocean processes near the Antarctic coast.

The ocean-sea ice model was run for a 37-yr spinup period initialized from the World Ocean Atlas 2013 v2 (WOA13v2) "decav" temperature and salinity fields (the average of six decadal climatologies spanning 1955-2012; Zweng et al. 2013; Locarnini et al. 2013) before two enhanced meltwater perturbation experiments (described in section $2 \mathrm{~b}$ ) were branched off. The perturbation experiments and control case were each run for a 10-yr experimental period. To remove the effect of interannual atmospheric variability, and to isolate ocean and sea ice responses to imposed meltwater changes, a repeat-year atmospheric forcing scheme is prescribed in both the spinup and the experimental period that repeats the JRA55-do v1.3 forcing from 1 May 1984 to 31 April 1985-a year selected to minimize the influence of anthropogenic warming and anomalies in major modes of climate variability on the model baseline state (Stewart et al. 2020). To avoid drifts in ocean salinity inherent to ocean-sea ice models due to the omission of atmospheric feedbacks, sea surface salinity is relaxed toward the WOA13v2 monthly climatology with a restoring piston velocity of $33 \mathrm{~m}$ (300 days) ${ }^{-1}$ (see Griffies et al. 2009). The 37 -yr spinup period is short, relative to the equilibration time of the global ocean, and as a result the model deep ocean state drifts over the experimental period. Model drift constitutes $20 \%$ and $45 \%$ of the volume averaged temperature trend south of $50^{\circ} \mathrm{S}$ and below 3000 $m$ depth over the two enhanced meltwater simulations. However, waters on the shallow Antarctic continental shelf, the focal region of this study, quickly adjust to surface forcings such that volume averaged temperature and salinity values for the region poleward of the 1000-m isobath do not drift significantly $(p>0.05)$ over the 10 -yr control simulation. To minimize the influence of model drift on our findings, we primarily consider anomalies between the 10-yr experimental and control simulations.
ACCESS-OM2-01 has a nominal horizontal grid length of $0.1^{\circ}$ and a 75 level $z^{*}$ vertical grid (see Stacey et al. 1995; Adcroft and Campin 2004), providing vertical grid spacing ranging from $1.1 \mathrm{~m}$ at the surface to $198.4 \mathrm{~m}$ at depth. Along the Antarctic continental shelf and slope, the focal region of this study, ACCESS-OM2-01 yields zonal and meridional grid spacing of $2.2-5.5$ and $4.7-5.5 \mathrm{~km}$, respectively. While representing a substantial improvement over previous studies, this horizontal resolution is insufficient to fully resolve the mesoscale eddy field along the ASF, where the Rossby radius is $\sim 4 \mathrm{~km}$ and a grid scale of $\sim 1 \mathrm{~km}$ is generally considered eddy resolving (Stewart and Thompson 2015; St-Laurent et al. 2013; Graham et al. 2016). No mesoscale eddy parameterizations are employed; thus cross-ASF eddy heat transport may be underrepresented in ACCESS-OM2-01. Additionally, the model omits tides, which have been suggested to modify the structure of the ASF (Flexas et al. 2015) and to contribute to the continental shelf heat budget (Stewart et al. 2018). Despite such deficiencies, the simulated temperature and salinity of Antarctic water masses on and adjacent to the continental shelf agree remarkably well with available observations, indicating that cross-ASF exchanges are well captured by the model. Figure 1 demonstrates broad consistency between observational estimates of Antarctic Shelf Bottom Water (ASBW) and CDW temperature and salinity by Schmidtko et al. (2014) and ACCESS-OM2-01 control simulation output, with both the spatial variability and the range of tracer concentrations well replicated by the model, although larger biases are evident in the Weddell Sea $\left(\sim 50^{\circ} \mathrm{W}\right)$ and Marie Byrd Land $\left(\sim 130^{\circ} \mathrm{W}\right)$. Note that, following Goddard et al. (2017), we define the Antarctic continental shelf as the region poleward of a continuous approximation of the 1000-m isobath (black contours in Fig. 1), a natural boundary choice as this isobath closely tracks the ASC and ASF (Goddard et al. 2017; Thompson et al. 2018).

The most salient success of ACCESS-OM2-01 in the Antarctic region is that it accurately simulates the known mechanisms of AABW formation from continental shelf sourced dense waters. Using monthly model output, a surface water-mass transformation analysis following Newsom et al. (2016) and Abernathey et al. (2016) reveals that Antarctic continental shelf surface waters transform into downwelling density classes $\left(\sigma_{1}>32.51 \mathrm{~kg} \mathrm{~m}^{-3}\right.$, where $\sigma_{1}$ is potential density referenced to $1000 \mathrm{dbar}$ ), forming DSW, at a rate of $11.6 \mathrm{~Sv}\left(1 \mathrm{~Sv} \equiv 10^{6} \mathrm{~m}^{3} \mathrm{~s}^{-1}\right)$. A map of transformation rates across $32.51 \mathrm{~kg} \mathrm{~m}^{-3}$ (Fig. 2, red shading) shows that DSW formation is simulated in the four regions recognized as $\mathrm{AABW}$ sources in observations: the Weddell Sea (Foster and Carmack 1976; Gordon et al. 1993), Ross Sea (Jacobs et al. 1970; Gordon et al. 2004, 2009), Adélie Coast (Williams et al. 2008; Foster 1995), 

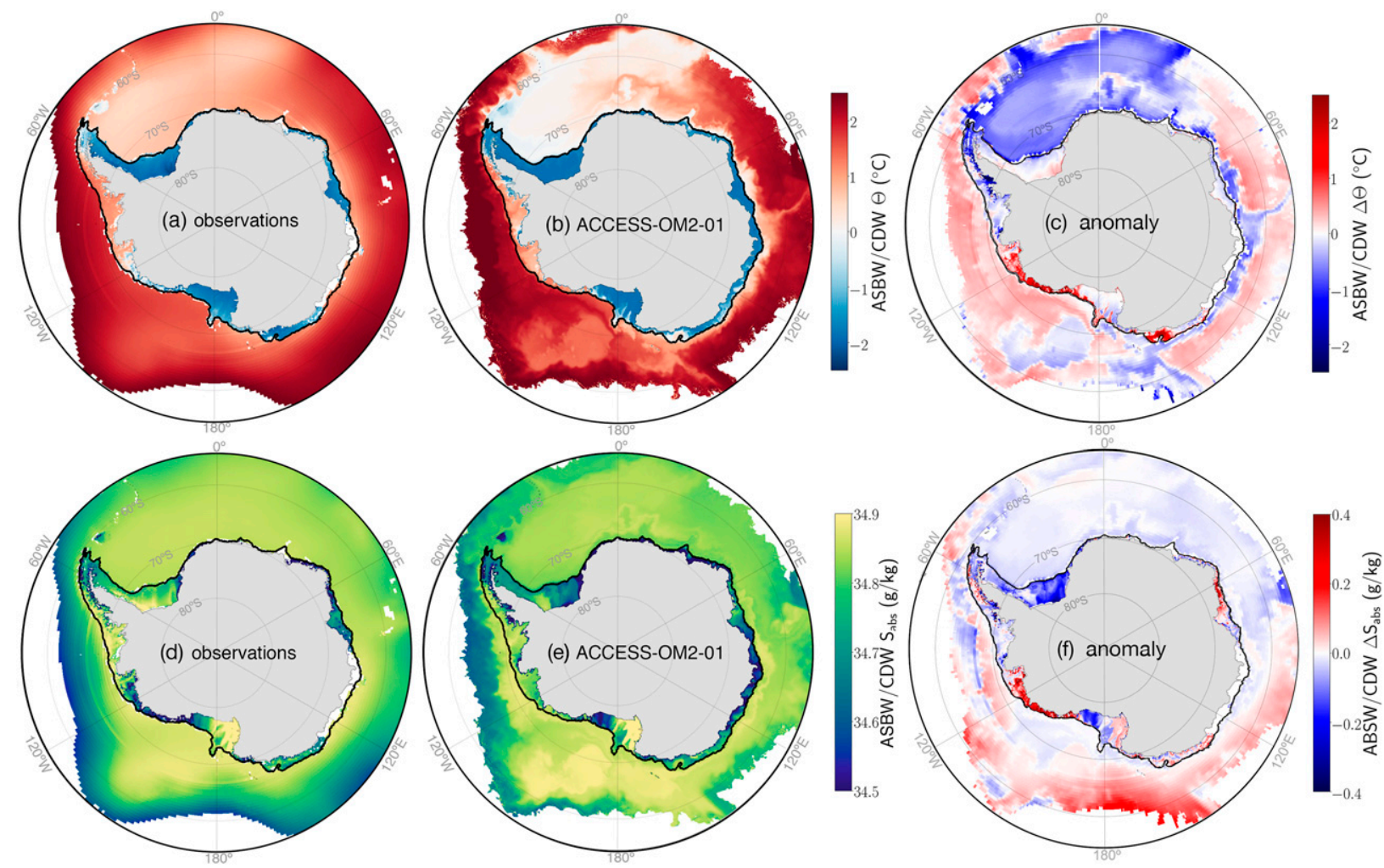

FIG. 1. Comparison of Antarctic water-mass properties in ACCESS-OM2-01 with observations. (a)-(c) Conservative Temperature and (d)-(f) Absolute Salinity of Antarctic Shelf Bottom Water (ASBW; shading poleward of black contour) and Circumpolar Deep Water (CDW; shading north of black contour) partitioned by the 1000-m isobath (black contour). Observational estimates in (a) and (d) are from Schmidtko et al. (2014), based on 1975-2012 data. Model values shown in (b) and (e) are averaged over the 10-yr control simulation. Model values are binned onto the observational grid and spatially averaged to generate anomalies in (c) and (f). ASBW is defined as the bottom ocean cell on the Antarctic continental shelf. Following Schmidtko et al. (2014), CDW characteristics are taken at the conservative temperature maximum below the Winter Water depth, where the Winter Water depth is defined as the Conservative Temperature minimum below 40-m depth. CDW is undefined where this Conservative Temperature maximum exceeds $2.8^{\circ} \mathrm{C}$. Regions where data are unavailable or water-mass definitions are unsatisfied are in white.

and Prydz Bay (Ohshima et al. 2013). In agreement with observational studies (Pellichero et al. 2018), densification on the shelf is driven by brine rejection from sea ice formation, with $95 \%$ of the DSW transformation rate attributable to salinity fluxes, and only $5 \%$ to cooling. Mapping the relative ideal ocean age in the bottom ocean grid cell (Fig. 2, green shading; a passive tracer is set to zero in the surface cell that increases with time in internal cells) reveals that these recently ventilated shelf-sourced dense waters cascade down the continental slope to the abyssal ocean along pathways consistent with observed AABW transports [see, e.g., Fig. 7e in Orsi et al. (1999)]. Most global ocean and climate models produce Antarctic dense waters in large open ocean convective cells dominated by surface heat fluxes, and where other global models successfully generate DSW through brine rejection on the continental shelf, excessive mixing in overflows diverts DSW into intermediate depths instead of exporting them to the abyssal ocean floor (Heuzé et al. 2013). In ACCESSOM2-01, DSW generated by sea ice processes is successfully exported to the deep ocean where it drives an abyssal overturning cell with a maximum transport of $25 \mathrm{~Sv}$ at $58^{\circ} \mathrm{S}$ that slows to $8 \mathrm{~Sv}$ at $30^{\circ} \mathrm{S}$ [discussed further by Kiss et al. (2019)]. The accurate representation of AABW formation from DSW overflows in ACCESS-OM2-01 constitutes a significant improvement in the representation of Antarctic ocean dynamics in global models, making it an ideal tool to interrogate the response of Antarctic circulation to climate perturbations.

ACCESS-OM2-01 successfully simulates Antarctic water-mass properties despite its simplified representation of Antarctic ocean forcing and boundaries. Since ACCESS-OM2-01 does not incorporate a dynamic ice sheet model, glacial meltwater inputs from basal melting and iceberg calving are combined and included in the control JRA55-do v1.3 forcing as a constant "runoff" flux with magnitude and spatial distribution informed by 


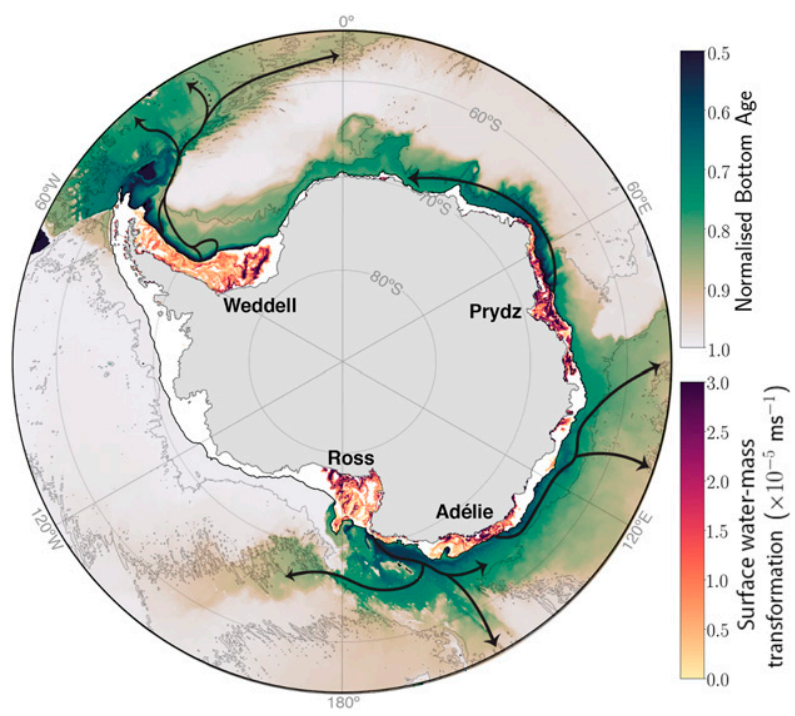

FIG. 2. Simulated dense water formation on the Antarctic continental shelf and transport pathways to the abyssal ocean in ACCESS-OM2-01. The surface water-mass transformation rate per unit area across $\sigma_{1}=32.51 \mathrm{~kg} \mathrm{~m}^{-3}$, into downwelling density classes (density classes experiencing time-mean volume convergence or water-mass "formation" that must be balanced by subduction at steady state; e.g., Pellichero et al. 2018), is shown on the continental shelf in red shading. Green shading in the open ocean shows passive age tracer values for the bottom ocean grid cell, normalized by the simulation length. Dark green shading indicates the presence of recently ventilated shelf-sourced dense waters at the seabed. Black arrows schematically interpret the pathways along which these shelfsourced dense waters propagate northward as AABW. Timeaveraged output for the 10 -yr control simulation is shown. Black and gray lines are the 1000- and 4000-m isobaths respectively, which delineate the continental shelf and abyssal ocean regions.

Depoorter et al. (2013). ACCESS-OM2-01 does not contain ice shelf cavities, and meltwater is simply input at the surface along the coastline, defined at the ice shelf perimeter. As such, our simulations neglect dynamics associated with circulation beneath floating ice shelves, the influx of meltwater at depth, and the advection of calved icebergs (e.g., Jourdain et al. 2017; Martin and Adcroft 2010; Mathiot et al. 2017; Schloesser et al. 2019). This omission contributes to the model tracer biases illustrated in Fig. 1; temperature and salinity biases simulated on the continental shelf in ACCESS-OM2-01 agree well with biases attributed to the input of glacial meltwater at the surface, instead of at depth, by Mathiot et al. (2017) (see Mathiot et al. 2017, their Figs. 12b,c).

\section{b. Meltwater forcing experiments}

Two enhanced meltwater experiments (Fig. 3) were conducted where the baseline JRA55-do v1.3 Antarctic runoff pattern was amplified to include projected Antarctic ice sheet mass loss rates at 2100 under the RCP4.5 and RCP8.5 scenarios. We constructed spatially variable meltwater perturbation scenarios guided by recent patterns of ice loss, rather than increasing the baseline runoff pattern by a spatially invariant scale factor (e.g., Snow et al. 2016) or employing a crude "hosing" where a uniform runoff rate is applied to the entire coastline (e.g., Swingedouw et al. 2009; Stouffer et al. 2007). Ice shelves for which significant thinning was observed by Paolo et al. (2015) for the 1994-2012 period were identified and aggregated into six regions experiencing similar rates of thinning; the Larsen Ice Shelves, West Antarctic Peninsula, Amundsen and Bellingshausen Seas, Ross Sea, Rennick Ice Shelf, and Dibble Ice Shelf (Figs. 3a,b). The 1994-2012 observed increases in glacial runoff rates due to thinning in these six regions (totaling a $0.008 \mathrm{~Sv}$ increase around Antarctica) were then amplified by a constant scale factor to total the magnitude of the Golledge et al. (2019) RCP4.5 and RCP8.5 at 2100 projected increases in runoff rates for the whole of Antarctica (0.042 and $0.160 \mathrm{~Sv}$ ). These amplified runoff values were then translated into six regional scaling factors by which the baseline runoff pattern (which contains variability at the ice shelf scale) was increased. The resulting runoff perturbations are illustrated in Fig. 3, with details, including scale factors, provided in Table 1 . These simulations are hereafter referred to as MW1.5 and MW2.8 as runoff perturbations of 0.042 and $0.160 \mathrm{~Sv}$ represent a scaling of the total Antarctic runoff of approximately 1.5 and 2.8 times the baseline JRA55-do value. The magnitude of these meltwater perturbations is comparable to experiments conducted by Snow et al. (2016), who included runoff amplifications of between 1.3 and 2.3 times baseline values, and is smaller than experiments utilizing Antarctic meltwater scenarios from DeConto and Pollard (2016) (e.g., Bronselaer et al. 2018; Lago and England 2019; Schloesser et al. 2019), who predict meltwater perturbations of approximately 0.6 and $0.2 \mathrm{~Sv}$ by 2100 under RCP8.5 and RCP4.5 forcing respectively. This methodology produces two idealized forcing scenarios with magnitudes considered to be conservative for the end of the century and a simplified spatial pattern that assumes the greatest near-future melt rates will occur in regions of recent observed ice shelf thinning and reduced buttressing. Due to the simplifications of this forcing rationale and the large uncertainties associated with projections of Antarctic melt rates, we caution readers against interpreting the results of this study in terms of RCP4.5 and RCP8.5 emissions scenarios.

The meltwater perturbations are imposed as step changes in the Antarctic runoff rate initiated at year 0 of the 10-yr experimental period, which starts in May in alignment with the repeat year atmospheric forcing. Prescribed meltwater increases are effectively damped over the experimental period by surface salt restoring fluxes, since restoring fluxes increase as the model ocean state tends further away from the WOA13v2 reference. 

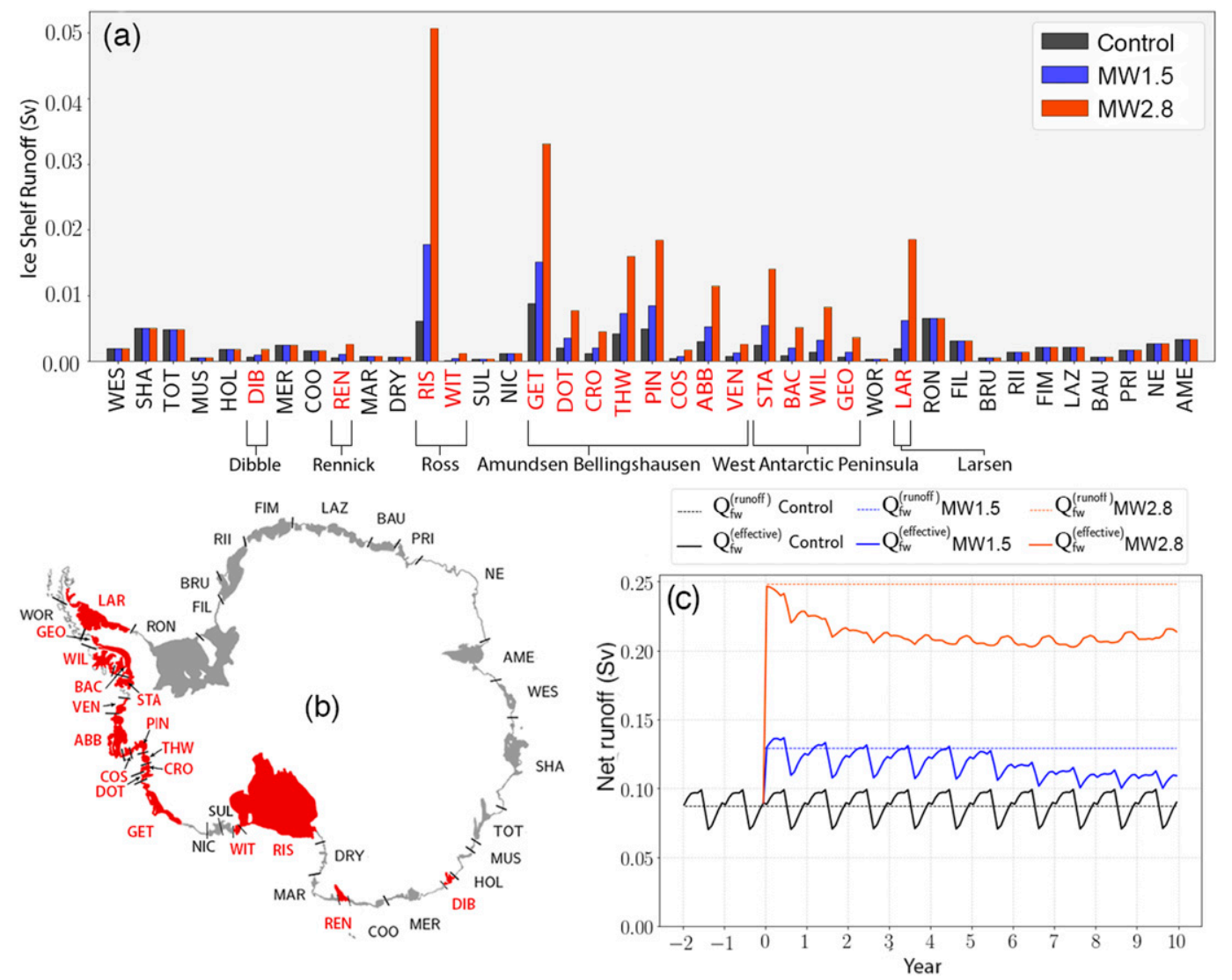

FIG. 3. Summary of the control and perturbed Antarctic runoff forcing schemes. (a) Runoff per ice shelf under the control (black), MW1.5 (blue), and MW2.8 (orange) scenarios. Ice shelves for which runoff is increased under the experimental forcing are highlighted in red and grouped into six regions (Dibble, Rennick, Ross, Amundsen and Bellingshausen, West Antarctic Peninsula, and Larsen) for which different scaling factors are used to amplify the control Depoorter et al. (2013) runoff pattern. (b) Map indicating ice shelf locations. Ice shelves contributing to meltwater perturbations are in red. (c) Time series of the total $Q_{\mathrm{fw}}^{\text {(total) }}$ and effective $Q_{\mathrm{fw}}^{\text {(effective) }}$ Antarctic runoff over the experimental period. All seasonal variability in $Q_{\mathrm{fw}}^{\text {(effective) }}$ is contained in the surface salinity restoration term [see Eq. (1)]. Ice shelf abbreviations: WES, West; SHA, Shackleton; TOT, Totten; MUS, Moscow; HOL; Holmes; DIB, Dibble; MER, Mertz; COO, Cook; REN, Rennick; MAR, Mariner; DRY, Drybalski; RIS, Ross Ice Shelf; WIT, Withrow; SUL, Sulzberger; NIC,Nickerson; GET, Getz; DOT, Dotson; CRO, Crosson; THW, Thwaites; PIN, Pine Island; COS, Cosgrove; ABB, Abbott; VEN, Venable; STA, Stange; BAC, Bach; WIL, Wilkins; GEO, George VI; WOR, Wordie; LAR, Larsen; RON, Ronne; FIL, Filchner; BRU, Brunt; RII, Riiser; FIM, Fimbul; LAZ, Lazarev; BAU, Baudouin; PRI, Prince Harald; NE, North East; AME, Amery.

A time series of the effective Antarctic runoff $Q_{\mathrm{fw}}^{\text {(effective) }}$ is shown in Fig. 3c, computed as

$$
Q_{\mathrm{fw}}^{(\text {(effective) }}=Q_{\mathrm{fw}}^{(\text {runoff })}-\left(10^{6} \rho_{0}\right)^{-1} \iint_{C}\left(F_{\text {salt }}^{(\text {restore })} / \mathrm{SSS}\right) d x d y,
$$

following Griffies et al. (2009), where $Q_{\mathrm{fw}}^{(\mathrm{runoff})}$ is the total runoff from the Antarctic continent (a constant value of 0.087, 0.129, and $0.248 \mathrm{~Sv}$ for the control, MW1.5, and MW2.8 scenarios respectively), SSS is the sea surface absolute salinity (converted to $\mathrm{kg} \mathrm{kg}^{-1}$ ) of a given grid cell experiencing a salt restoring flux of $F_{\text {salt }}^{\text {(restore) }}\left(\mathrm{kg} \mathrm{m}^{-2} \mathrm{~s}^{-1}\right), C$ is the region poleward of the $1000-\mathrm{m}$ isobath, $\rho_{0}$ is a reference freshwater density set to $10^{3} \mathrm{~kg} \mathrm{~m}^{-3}$, and the factor $\left(10^{6} \rho_{0}\right)^{-1}$ converts freshwater fluxes from $\mathrm{m}^{3} \mathrm{~s}^{-1}$ to $\mathrm{Sv}$. Due to damping by surface salinity restoring, effective runoff anomalies averaged over the final year of the experimental period are $48 \%$ (MW1.5) and 77\% (MW2.8) of their prescribed values. Given the uncertainties inherent to Antarctic runoff projections, and since we are interested in identifying the dynamical drivers of feedbacks to ice shelf melt as opposed projecting the ocean state along a specific emissions trajectory, we did not attempt to counteract the effect of surface salinity restoration.

\section{Results}

Under the MW1.5 and MW2.8 enhanced meltwater forcing schemes, Antarctic continental shelf waters 
TABLE 1. Baseline and perturbed runoff from Antarctic ice shelves in six enhanced runoff regions shown in Fig. 3. Perturbation magnitudes are determined by scaling up runoff increases inferred from thinning rates over the 1994-2012 period by Paolo et al. (2015) [volume fluxes reported by Paolo et al. (2015) are converted to mass fluxes assuming an ice density of $\rho_{\text {ice }}=0.917 \mathrm{~kg} \mathrm{~m}^{-3}$ ]. Scale factors (SF), shown in square brackets, are used to generate final runoff patterns, in order to retain spatial variability at the ice shelf scale in the control JRA55-do forcing. Refer to Figs. 3a and 3b for region definitions.

\begin{tabular}{|c|c|c|c|c|}
\hline Region & $\begin{array}{c}\text { Control } \\
\operatorname{runoff}^{\mathrm{a}}\left(\mathrm{GT}_{\mathrm{yr}}{ }^{-1}\right)\end{array}$ & $\begin{array}{c}\text { Observed } \\
\text { increase }^{\mathrm{b}}\left(\mathrm{GT}_{\mathrm{yr}}{ }^{-1}\right)\end{array}$ & $\begin{array}{l}\text { MW1.5 increase } \\
{\left[\mathrm{GT} \mathrm{yr}{ }^{-1}(\mathrm{SF})\right]}\end{array}$ & $\begin{array}{c}\text { MW2.8 increase } \\
{\left[\mathrm{GT} \mathrm{yr}^{-1}(\mathrm{SF})\right]}\end{array}$ \\
\hline Dibble & 22.4 & +1.8 & $+9.6[\times 1.08]$ & $+36.8[\times 2.64]$ \\
\hline Rennick & 8.5 & +1.8 & $+9.6[\times 2.13]$ & $+36.8[\times 5.32]$ \\
\hline Ross & 196.0 & +70.6 & $+375.5[\times 2.92]$ & $+1441.5[\times 8.35]$ \\
\hline $\begin{array}{l}\text { Amundsen } \\
\text { Bellingshausen }\end{array}$ & 805.5 & +108.2 & $+575.6[\times 1.71]$ & $+2209.2[\times 3.74]$ \\
\hline $\begin{array}{l}\text { West Antarctic } \\
\text { Peninsula }\end{array}$ & 276.2 & +39.4 & $+209.6[\times 2.19]$ & $+804.4[\times 5.57]$ \\
\hline Larsen & 55.5 & +25.7 & $+136.7[\times 3.46]$ & $+524.7[\times 10.45]$ \\
\hline $\begin{array}{l}\text { Runoff anomaly } \\
\qquad\left(\mathrm{GT} \mathrm{yr}^{-1}\right)\end{array}$ & - & +247.5 & +1306.6 & +5053.4 \\
\hline Runoff anomaly (Sv) & - & +0.008 & +0.042 & +0.160 \\
\hline
\end{tabular}

a Tsujino et al. (2018).

b Paolo et al. (2015).

freshen on average by 0.23 and $0.54 \mathrm{~g} \mathrm{~kg}^{-1}$, respectively, computed as the time-mean anomaly relative to the control for the 10th year of the experiment. The freshening signal is circumpolar, despite the concentration of prescribed runoff increases to West Antarctica (see Fig. 3b), and is constrained to the continental shelf poleward of the $1000-\mathrm{m}$ isobath (Figs. 4b,c). This shelf freshening prompts changes in the dynamics governing water-mass formation near the Antarctic coastline and water-mass exchange across the continental shelf margin in ACCESSOM2-01 as explored in the following sections. First, we present a qualitative circumpolar overview of shifts in leading-order shelf break dynamics triggered by the imposed freshening (section 3a). Then, we consider two distinct dynamical responses to freshening that contribute to this circumpolar signal: the decline of DSW overturning (section 3b) and the acceleration of near-Antarctic geostrophic flows (section 3c). Finally, these dynamical responses are employed in combination to explain temperature responses to freshening simulated on the continental shelf and slope (section 3d).

\section{a. Leading-order shelf break dynamics}

The leading-order dynamics influencing cross-slope transport vary substantially around the Antarctic continental margin at steady state, with some stretches characterized by strong interactions between shelf and open ocean water masses (e.g., DSW overflows), and others characterized by relative isolation (e.g., ASF isopycnal incropping). Following Thompson et al. (2018), we obtain a circumpolar overview of meltwater-induced shifts in cross-slope dynamics using a categorization framework based on the frontal structures and water-mass characteristics found near the shelf break.

Cross-slope annual mean temperature and potential density profiles are used to classify stretches of the Antarctic continental shelf into four categories with distinct dynamics; Fresh shelf, Warm shelf, Dense shelf, and Cool shelf (examples shown in Figs. $4 d-g$ ). The Fresh, Warm, and Dense shelf categories were introduced by Thompson et al. (2018), while the Cool shelf classification is included in the present study to account for a previously undocumented regime simulated in the eastern Ross Sea in ACCESS-OM2-01. The Fresh shelf case (Fig. 4d) typifies the ASF as described in section 1, where density surfaces tilt steeply downward toward the pole, maintaining strong lateral gradients in subsurface water-mass properties and preventing along-isopycnal pathways for CDW transport to the shelf. We identify the Fresh shelf regions where potential density contours containing open ocean warm waters $\left(\theta>0^{\circ} \mathrm{C}\right)$ intersect with the continental slope, and no warm waters $(\theta>$ $0^{\circ} \mathrm{C}$ ) are found poleward of the shelf break. The Dense shelf classification (Fig. 4e) captures DSW overflow sites. This regime is often associated with a V-shaped isopycnal geometry wherein (poleward) downward sloping isopycnals of the ASF intersect with (equatorward) downward sloping isopycnals along which DSW accesses the deep ocean. Here, Dense shelf sections are defined where isopycnal connections exist between cold $\left(\theta>0^{\circ} \mathrm{C}\right)$ shelf waters and the open ocean below 1500-m depth. The Warm shelf regime (Fig. 4f) describes conditions found along the West Antarctic Peninsula and Amundsen Sea; here the ASF frontal structure is weak 


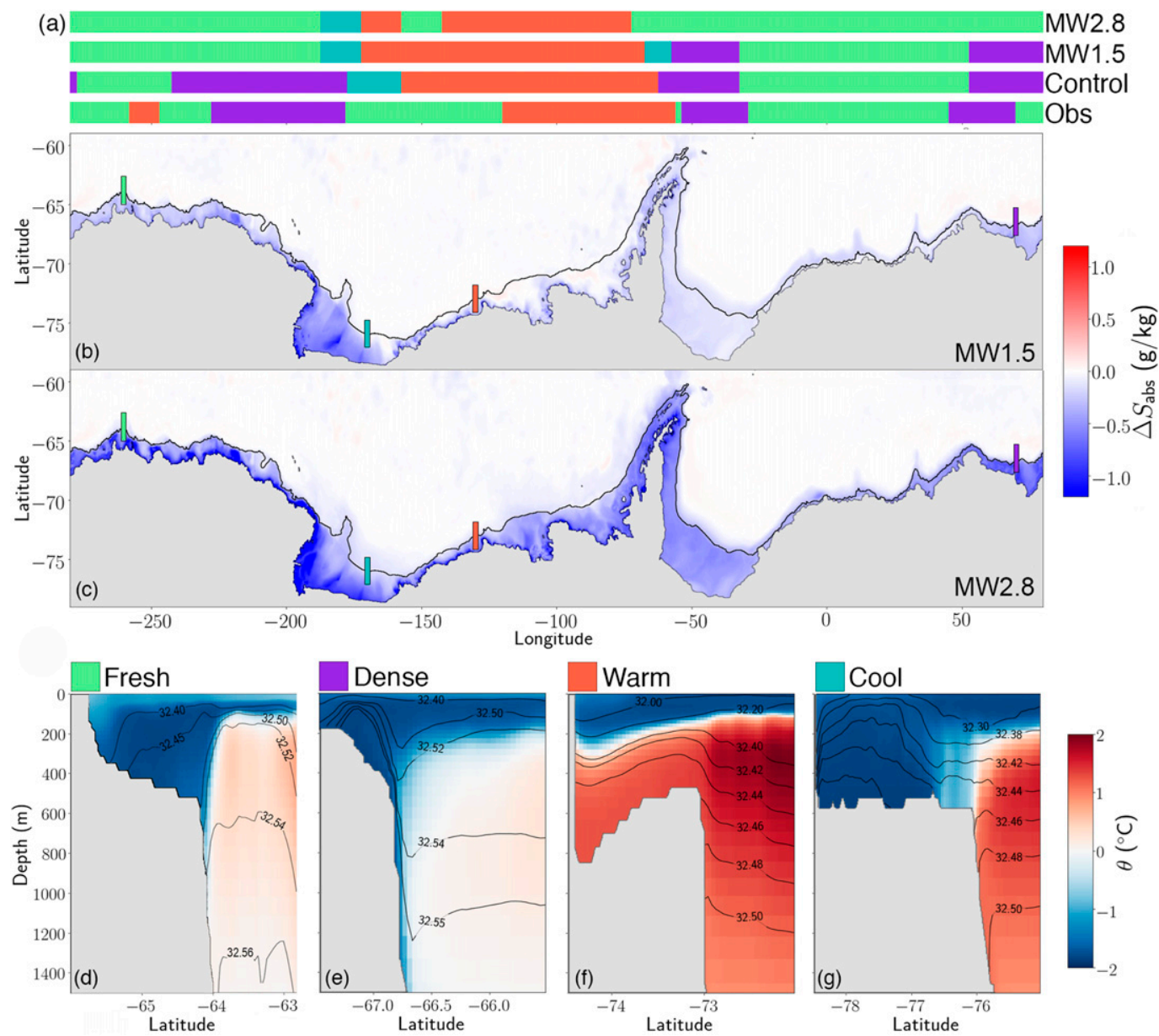

FIG. 4. (a) Classification of cross-slope profiles into Fresh (green), Cool (blue), Warm (red), and Dense (purple) categories described in the main text, shown as a function of longitude. The four color bars correspond to the Thompson et al. (2018) characterization based on observations (Obs), and ACCESS-OM2-01 output from the control, MW1.5, and MW2.8 simulations averaged over the 10th year of the experiment. The Fresh shelf regime is defined where $\sigma_{1}$ contours containing open ocean warm waters $\left(\theta>0^{\circ} \mathrm{C}\right)$ intersect with the continental slope, and no warm waters $\left(\theta>0^{\circ} \mathrm{C}\right)$ are found poleward of the shelf break. Dense shelf sections are defined where isopycnal connections exist between cold $\left(\theta<0^{\circ} \mathrm{C}\right)$ shelf waters and the open ocean below 1500-m depth. Warm shelf regions are defined where $\theta>0^{\circ} \mathrm{C}$ water is found on the shelf, except where the Dense shelf classification is also satisfied. The Cool shelf regime is defined where no $\theta>0^{\circ} \mathrm{C}$ water is found on the shelf, despite the absence of frontal barriers or DSW overflows at the shelf break. The control pattern does not drift over the 10-yr experimental period. (b),(c) Maps show upper 1000-m depth mean absolute salinity anomalies averaged over the final year of the experiment. Black contours are the 1000-m isobath. (d)-(g) Example transects from the control simulation illustrating the four shelf break regimes. Shading is potential temperature, while contours indicate isosurfaces of potential density $\sigma_{1}$. Transect locations are indicated in (b) and (c) by corresponding colored bars.

or absent, and CDW floods the continental shelf, uninhibited by the isopycnal tilting. We classify any region where warm waters $\left(\theta>0^{\circ} \mathrm{C}\right)$ are present on the shelf as a Warm shelf region, except where the Dense shelf classification is also satisfied. The characteristic dynamics of the Fresh, Warm, and Dense shelf regimes are described in detail by Thompson et al. (2018). Finally, a fourth catergorization, Cool shelf (Fig. 4g), is included to account for transects in the eastern Ross Sea where strong cross-slope temperature gradients are sustained (no $\theta>0^{\circ} \mathrm{C}$ water on the shelf) despite the absence of a frontal barriers or DSW overflows at the shelf break. Shelf water-mass properties in the east Ross Sea resemble those of Fresh shelf regions in east Antarctica (Fig. 1); however, CDW adjacent to the Ross Sea shelf is warmer and lighter than waters north of the shelf break in East Antarctica, and so no strong lateral density gradients persist between open ocean and shelf water masses. 

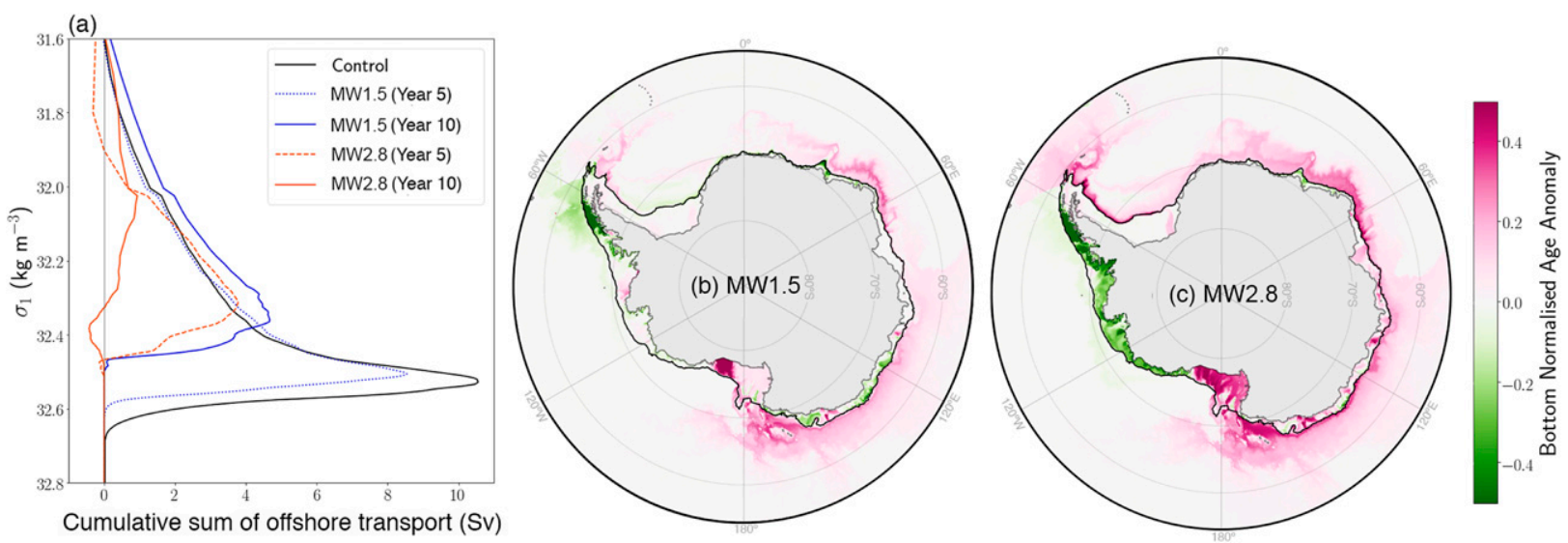

FIG. 5. (a) Net offshore transport across the 1000-m isobath, cumulatively summed in $\sigma_{1}$ space from high to low density. Transports are averaged over the 5th (dashed) and final (solid) years of the control (black), MW1.5 (blue), and MW2.8 (orange) simulations. Offshore transports do not drift over the control simulation, so only values for the 10th year are shown. (b),(c) Age anomalies for the bottom ocean cell, averaged over the final year of the MW1.5 and MW2.8 experiments, respectively, and normalized by the simulation length. Black lines denote the 1000-m isobath. Open ocean normalized bottom age anomalies for the control simulation are provided in Fig. 2.

Figure 4a provides the circumpolar distribution of continental shelf regimes in ACCESS-OM2-01 according to the above scheme, and summarizes shifts in shelf break dynamics triggered by the MW1.5 and MW2.8 meltwater forcing schemes. Under control forcing, the spatial distribution of continental shelf regimes in ACCESS-OM2-01 agrees well with the classification proposed by Thompson et al. (2018) (included in Fig. 4a for reference) derived from an observational dataset of water-column measurements (1D) and hydrographic profiles (2D). Discrepancies between observation and model-derived classifications are likely due to a combination of observational ambiguity (especially in regions where only 1D profiles are available) and model bias. The spatial distribution of shelf regimes alters substantially under MW1.5 and MW2.8 meltwater forcing, suggesting major shifts in the dynamics dictating continental shelf water-mass properties. The most notable trends are 1) contraction (MW1.5) and eventual elimination (MW2.8) of the Dense shelf regime, which is replaced by Fresh and Cool shelf structures, 2) increasing prevalence of the Fresh shelf regime, and 3) extension of Warm shelf properties westward into the eastern Ross Sea shelf (Fig. 4a). Overwhelmingly, the shelf becomes more isolated, in that a smaller fraction of the shelf has isopycnal connections with middepth open-ocean waters.

\section{b. Dense shelf water formation and export}

The declining prevalence of the Dense shelf dynamical regime points to a meltwater-induced slowdown of DSW formation. Within the 10-yr MW1.5 and MW2.8 meltwater perturbation experiments, surface buoyancy losses from Antarctic sea ice production cease to generate shelf waters of sufficient density to consistently cascade down the continental slope and contribute to abyssal overturning circulation. The density characteristics of waters exchanged between the continental shelf and the open ocean are analyzed by conservatively binning daily averaged volume transports across the $1000-\mathrm{m}$ isobath into potential density classes before taking an annual mean and integrating time-averaged fluxes from high to low density (Fig. 5a). Under control forcing, shelf waters denser than $\sigma_{1}=32.53 \mathrm{~kg} \mathrm{~m}^{-3}$ flow offshore across the $1000-\mathrm{m}$ isobath at a rate of $10.6 \mathrm{~Sv}$, in agreement with observational estimates that $8.1 \pm 2.6 \mathrm{~Sv}$ of AABW precursor waters are transported offshore across the upper continental slope (Orsi et al. 1999, 2002). Under enhanced meltwater forcing, both the rate of net offshore transport in higher-density classes and the density of waters transported off the shelf decline (Fig. 5a). By the fifth year of MW2.8 forcing (orange dashed line in Fig. 5a) and 10th year of MW1.5 forcing (solid blue line, Fig. 5a) the density of waters exported off the shelf resemble continental slope middepth and surface waters (see, e.g., cross slope transects in Fig. 4b), suggesting these waters cannot cascade to the abyssal ocean and contribute to AABW. Figures $5 \mathrm{~b}$ and $5 \mathrm{c}$ show that bottom waters along the abyssal AABW transport pathways highlighted in Fig. 2 increase in age in response to meltwater forcing, supporting a decline in the transport of recently ventilated DSW to the abyssal ocean. Figures $5 \mathrm{~b}$ and $5 \mathrm{c}$ also show strong negative ideal age anomalies along the West Antarctic continental shelf, which will be discussed in section $3 \mathrm{~d}(3)$.

Bottom shelf waters in DSW source regions likewise increase in age in response to freshening, particularly in the Ross Sea (Figs. 5b,c). This aging signal, in conjunction 
(a)

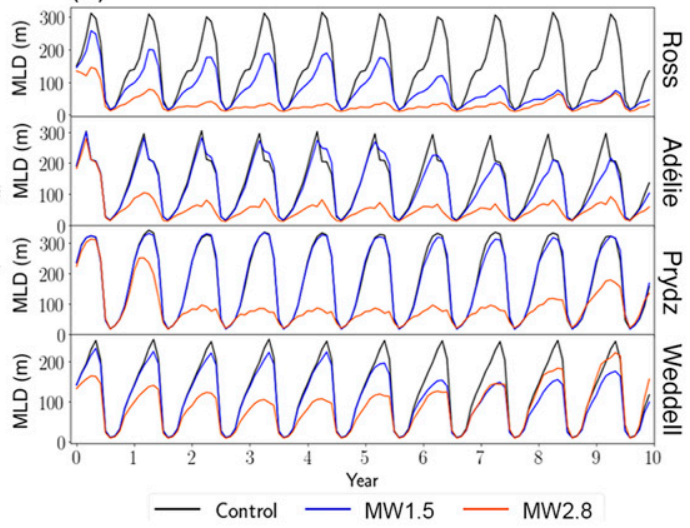

(c)

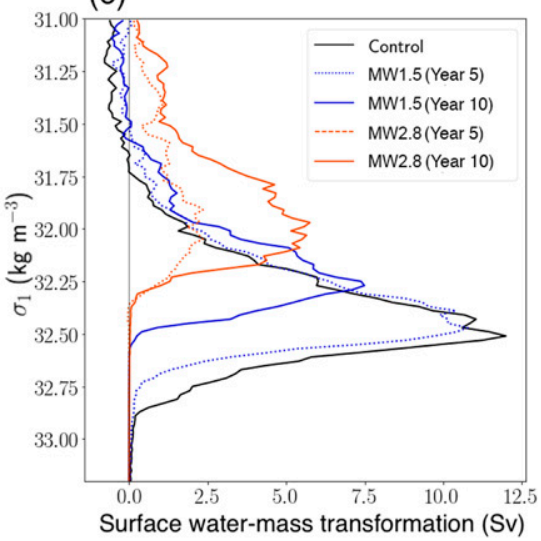

FIG. 6. (a) Time series of monthly mean mixed layer depths (MLD) spatially averaged over the four continental shelf regions that generate DSW under the control forcing. MLD is diagnosed as the depth at which potential density ( $\sigma_{0}$; referenced to 0 dbar) exceeds the surface density by $0.03 \mathrm{~kg} \mathrm{~m}^{-3}$. (b) Map of regions over which spatial averages are computed in (a). (c) Surface water-mass transformation rates integrated over the Antarctic continental shelf region (poleward of the 1000-m isobath) and averaged over the 5th (dashed) and 10th (solid) years of the experimental period for the control (black), MW1.5 (blue), and MW2.8 (orange) simulations. Transformation rates, which are calculated using monthly mean model output, do not drift over the control simulation, so only values for the 10th year of this run are shown.

with a decline in winter mixed layer depths in DSW source regions (Fig. 6a), suggests that coastal freshening triggers increased ocean stratification and a decrease in full-depth convection on the shelf. Where winter convection persists on the shelf, the density of downwelling surface waters is substantially reduced, as revealed by a surface water-mass transformation calculation (Fig. 6c). Surface water-mass transformation is defined as the volume flux into a given density class from lighter density classes due to surface buoyancy forcing, and is computed here as in Newsom et al. (2016). Note the convergence of the surface water-mass transformation rate is interpreted as the time-mean water-mass formation rate in a given density class, with positive formation indicating upwelling and negative formation indicating downwelling (e.g., Brambilla et al. 2008; Pellichero et al. 2018). Thus, maximum positive transport values in Fig. $6 c$ approximate the rate of surface process driven transformation into downwelling density classes. Values below this maximum (higher $\sigma$ ) provide a density range for downwelling waters, while values above this maximum (lower $\sigma$ ) provide a density range for upwelling waters. Under meltwater forcing both the rate of transformation into downwelling density classes and the density of downwelling waters decline, signaling declining rates of DSW generation by surface processes and declining DSW densities. As in Newsom et al. (2016), the use of monthly model output in surface water-mass transformation computations neglects the contribution of higher-frequency fluctuations in surface heat and freshwater fluxes to the formation of water masses. However, agreement between the density and rate of downwelling obtained from this surface water-mass transformation analysis (Fig. 6c), and the density and rate of DSW overflow across the 1000-m isobath derived from daily model output (Fig. 5a), suggests that monthly data adequately characterize the surface buoyancy fluxes driving DSW formation in ACCESS-OM2-01. The generation of DSW declines despite increasing sea ice production; timemean sea ice formation rates on the continental shelf are $7 \%$ and $17 \%$ greater in the MW1.5 and MW2.8 simulations than in the control, although the drivers of this trend are unclear. Combined, these trends suggest buoyancy losses from relatively vigorous sea ice activity may be counteracted by freshening from glacial meltwater, and therefore fail to generate DSW.

\section{c. Fronts and geostrophic currents}

Frontal Fresh shelf dynamics dominate the Antarctic shelf margin in the MW1.5 and MW2.8 simulations (Fig. 4a), suggesting that shelf waters become increasingly isolated from open ocean $\mathrm{CDW}$ in response to coastal freshening. While the classification framework used in Fig. 4 reveals that ASF structures are more commonplace in the MW1.5 and MW2.8 simulations than in the control, analysis of geostrophic flows dynamically linked to the ASF reveals that frontal barriers partitioning shelf waters from CDW also strengthen under enhanced meltwater forcing. The subsurface lateral density gradients and sloping isopycnals of the ASF are geostrophically balanced by the westward, vertically sheared Antarctic Slope Current (ASC) at the shelf break, and Antarctic Coastal Current (CC) along the ice 


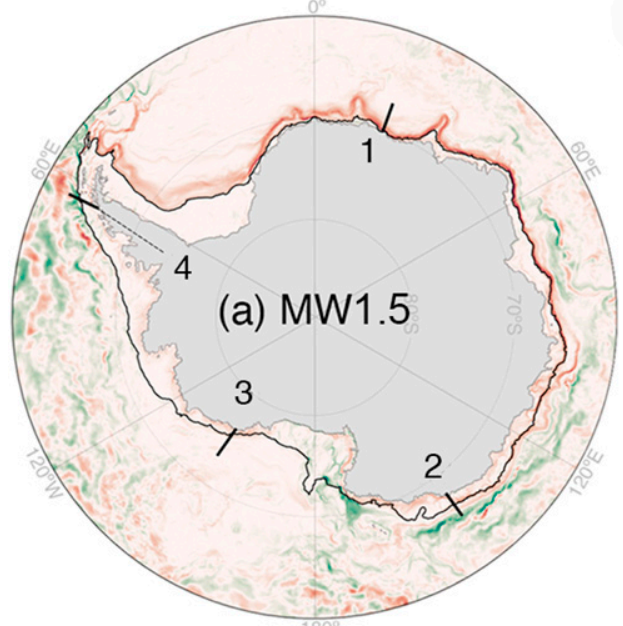

(c) 1-Queen Maud Land

(d) 2-Adélie Coast
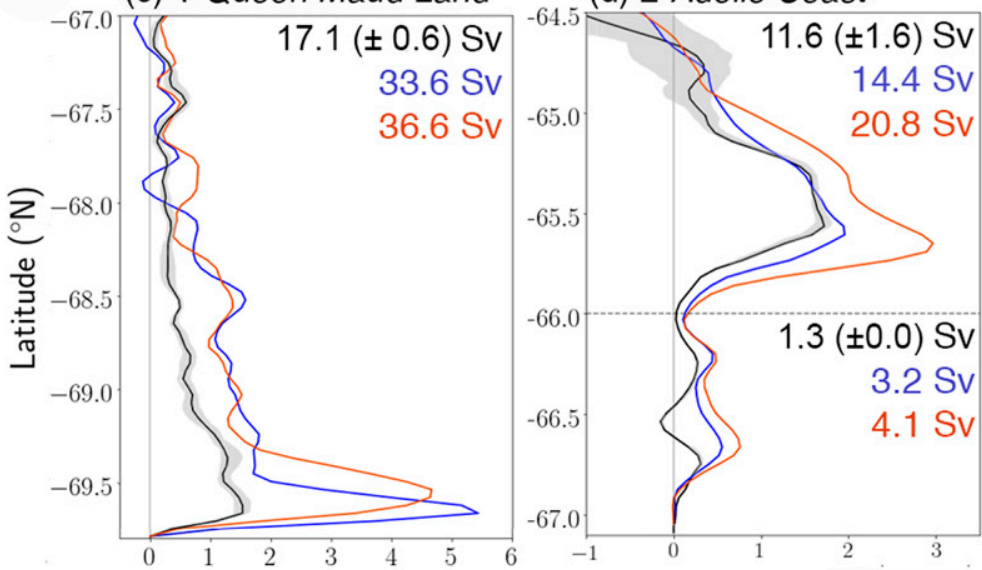

(e) 3-Marie Byrd Land
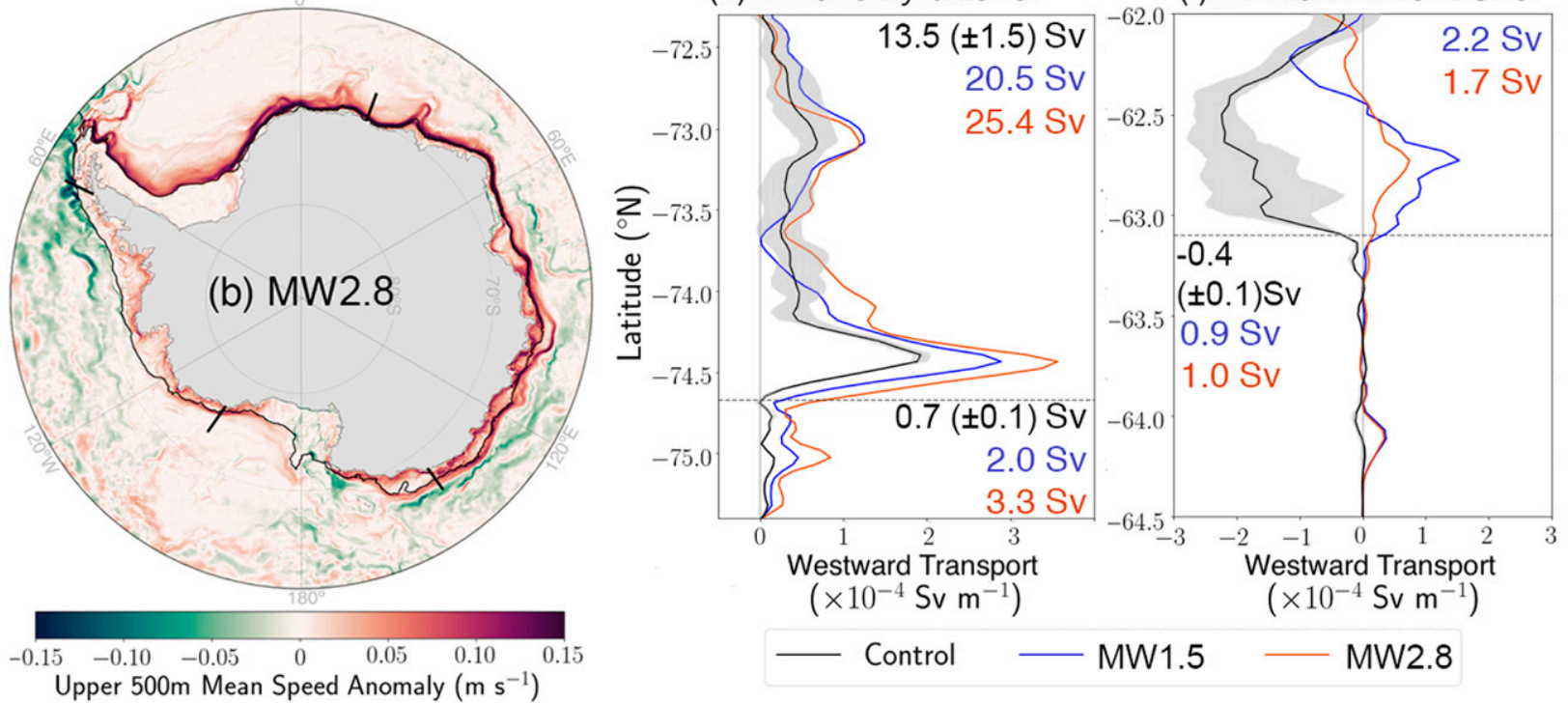

FIG. 7. Acceleration of the ASC and CC under enhanced meltwater forcing is illustrated by anomalies in the upper 500-m depth averaged flow speed (with respect to the control simulation) averaged over the (a) MW1.5 and (b) MW2.8 simulations. The 1000-m isobath is delineated by black contours. (c)-(f) Full depth integrated westward transport across four cross-slope transects in Queen Maud Land, the Adélie Coast, Marie Byrd Land, and the Antarctic Peninsula, respectively. Transect locations are indicated by thick black lines and numbering in (a). Time mean flow rates averaged over the 10-yr control simulation are shown in black with gray shading indicating the extent of interannual variability. Annual mean flow rates are shown for the final year of the perturbed experiments in blue (MW1.5) and orange (MW2.8). Dashed lines indicating where the transect intersects with the 1000-m isobath, a boundary used here to partition flow associated with the CC (peak poleward of isobath) from flow associated with the ASC (peak north of isobath). Inset values are the total westward transport of the CC (below dashed line) and ASC (above dashed line) across the transects, computed by integrating plotted values from the coastline the the 1000-m isobath for CC transports, and from the 1000-m isobath [or coastline, in (c)] to the point where the net zonal transport switches from westward to eastward (crossing the 0 transport line shown). Negative values indicate eastward CC transport and there is no ASC flow (which is exclusively defined as westward flow) across the Antarctic Peninsula transect in the control simulation in (f).

shelf perimeter. Over the MW1.5 and MW2.8 simulations, the ASC and CC accelerate (Fig. 7), as strong negative salinity anomalies near the coast strengthen the meridional density gradients across the continental shelf and slope that drive the flow (Fig. 8). Depth integrated zonal transports computed across four cross-slope transects spread across East and West Antarctica show that westward ASC transport increases by $44 \%-91 \%$ under MW1.5 forcing and by $83 \%-108 \%$ under MW 2.8 forcing where the ASC is defined as the region of net westward flow north of the 1000-m isobath (Figs. 7c-e). Poleward of the 1000-m isobath, where the CC is defined, westward transport more than doubles in the MW1.5 simulation, and more than triples in the MW2.8 experiment (Figs. 7d,e). Further, coastal freshening initiates a westward ASC and CC along the Antarctic Peninsula (Fig. 7f), where proximity to the Antarctic Circumpolar Current (ACC) drives eastward flow under control forcing. The strengthening of the ASF 


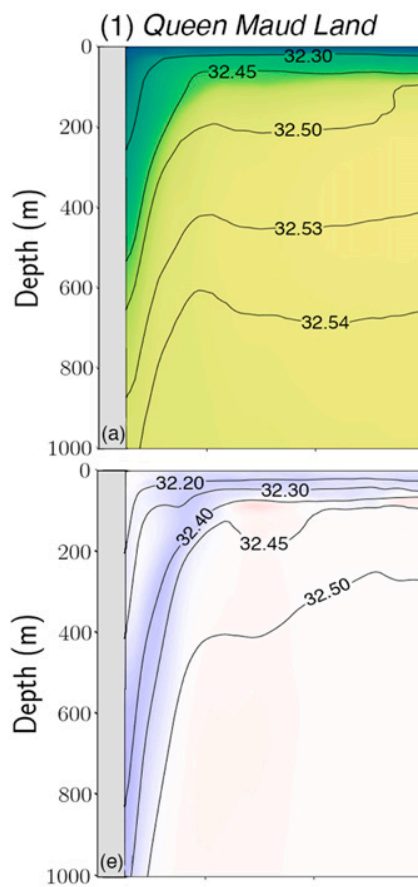

(2) Adélie Coast

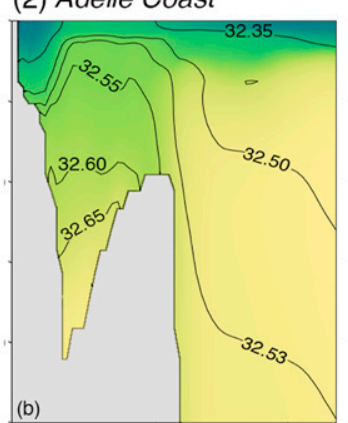

(b)
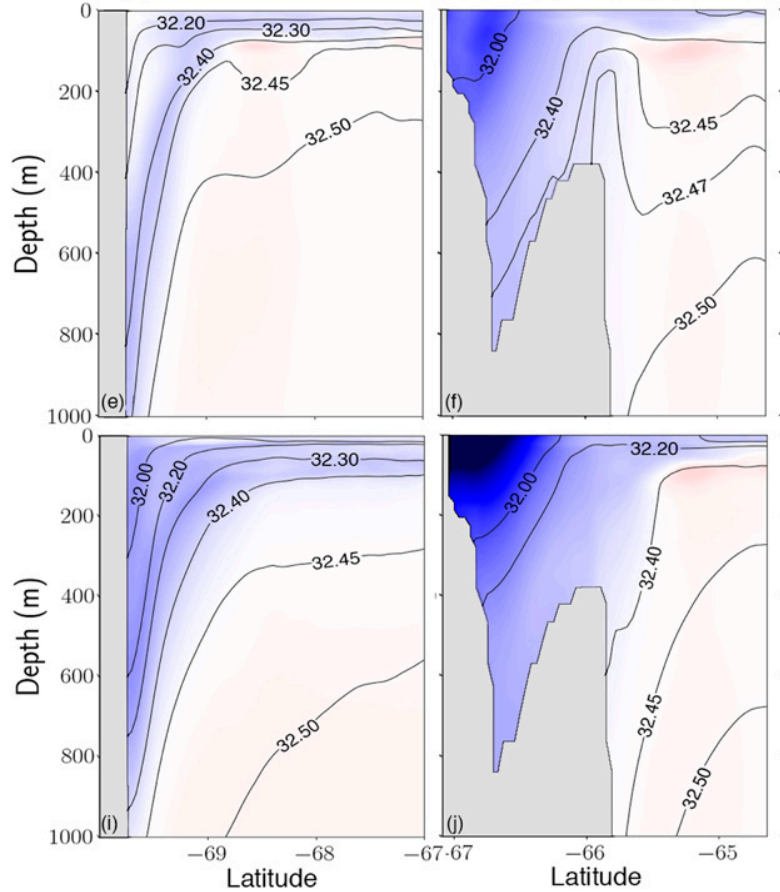

(3) Marie Byrd Land
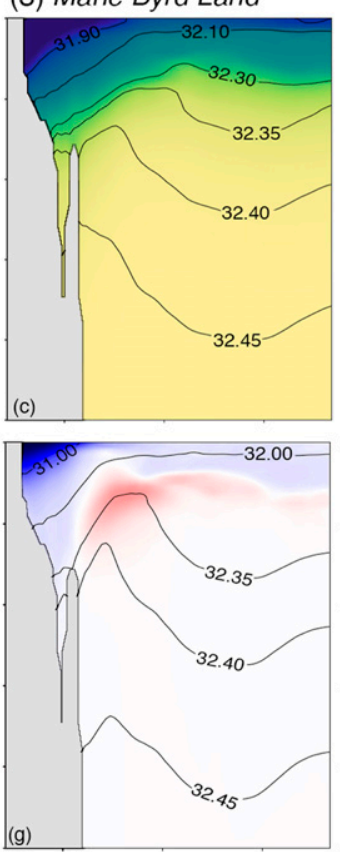

.

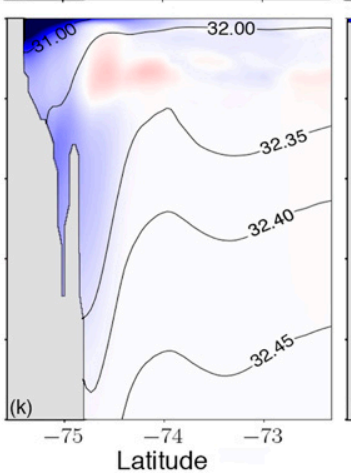

(4) Antarctica Peninsula
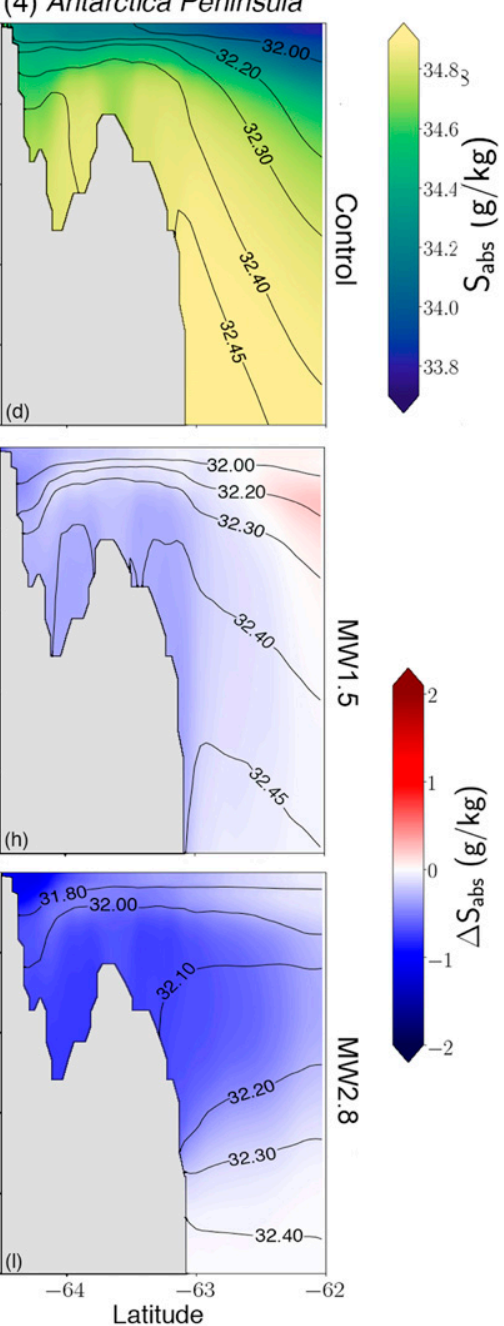

FIG. 8. (a)-(d) Depth profiles of $\sigma_{1}$ (contours) and absolute salinity (shading) along the four cross-slope transects considered in Fig. 7. Time-mean values for the final year of the control simulation are shown. Salinity anomalies (shading) averaged over the final year of the (e)-(h) MW1.5 and (i)-(l) MW2.8 simulations, relative to the control simulation. Contours show time-mean (absolute) $\sigma_{1}$ values for the final year of the experiments.

and ASC system at the Antarctic continental shelf break suggests that coastal freshening can act to limit interaction between Antarctic shelf waters from open ocean water masses, isolating the shelf from open ocean heat sources, while the acceleration of the $\mathrm{CC}$ suggests shelf waters may become increasingly homogeneous in response to freshening, as gradients between adjacent shelf water masses are dampened by increasing alongshore tracer fluxes.

\section{d. Antarctic ocean temperature response}

\section{1) MEAN SHELF AND SLOPE RESPONSE}

In ACCESS-OM2-01, Antarctic coastal freshening triggers consistent subsurface warming of continental slope waters, yet generates spatially and temporally variable temperature signals on the continental shelf that suggest a complex pattern of positive and negative thermal feedbacks to ice shelf melt (Fig. 9). We conduct a heat budget analysis of the continental shelf region and, in subsequent sections, select subdomains of the shelf in order to interpret these heterogenous thermal responses. Following Goddard et al. (2017), we compute heat flux terms relative to a constant reference seawater freezing temperature $\theta_{f}$ set to the minimum freezing point found along the $1000-\mathrm{m}$ isobath over the three simulations, $\theta_{f}=-2.97^{\circ} \mathrm{C}$. This choice of reference temperature eases the interpretation of heat budgets by ensuring the direction of local heat and volume fluxes align where ocean temperatures drop below $0^{\circ} \mathrm{C}$, and represents an upper bound on the melt potential of transports as the true value of $\theta_{f}$ varies in space and time. 


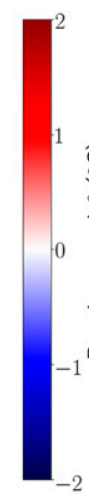

(a)

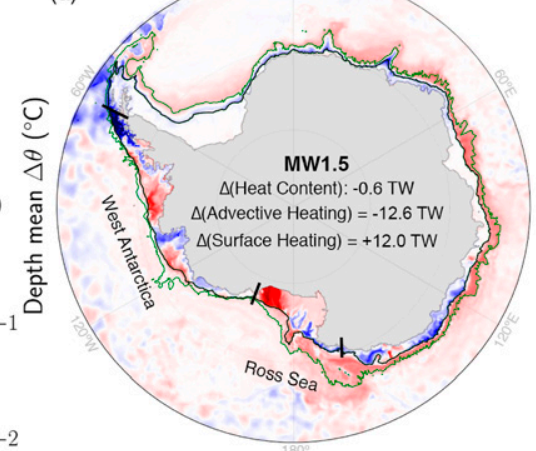

(d) Ross Sea Sector (MW1.5)

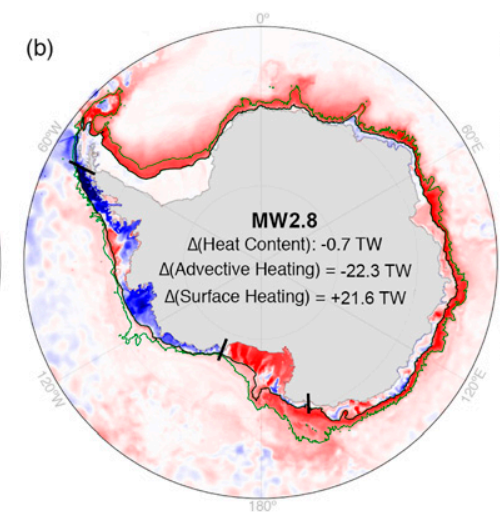

(e) Ross Sea Sector (MW2.8)

(f) West Antarctic Sector (MW1.5)

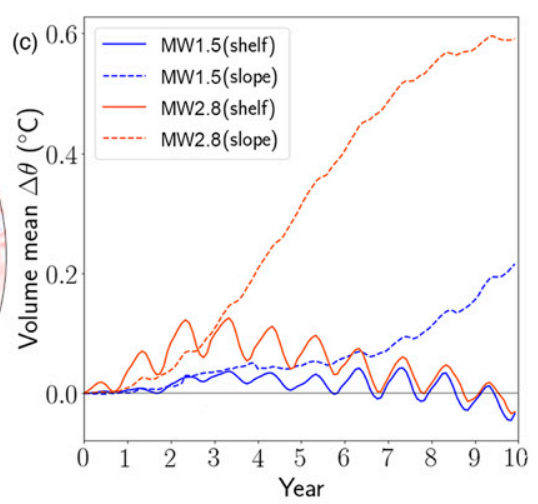

(g) West Antarctic Sector (MW2.8)

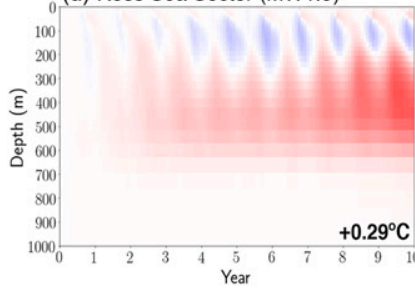

11
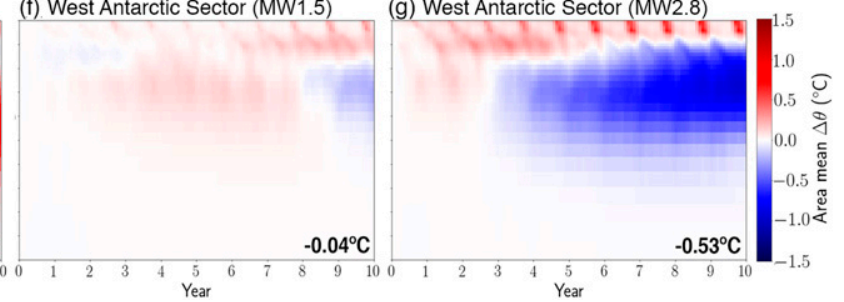

FIG. 9. (a),(b) Depth-mean temperature anomalies of the MW1.5 and MW2.8 simulations compared with the control, averaged over the final year of the experimental period. Inset values summarize the continental shelf heat budget, averaged over the experimental period, shown as an anomaly relative to the control simulation. Note that the time-mean advective and surface heat fluxes into the region are +43.8 and -43.6 TW respectively for the control simulation. Heat fluxes are computed relative to a reference temperature of $\theta_{f}=-2.97^{\circ} \mathrm{C}$. Black contours mark the $1000-\mathrm{m}$ isobath, while green contours show a continuous approximation of the 3000-m isobath. Thick black lines partition the Ross Sea and West Antarctica continental shelf regions considered in (d)-(g). (c) Time series of monthly mean volume-averaged temperature anomalies on the continental shelf (solid lines are for the region poleward of the $1000 \mathrm{~m}$ isobath) and continental slope (dashed lines are for the region between the 1000- and 3000-m isobaths). Anomalies are computed relative to the control simulation. Potential temperature anomalies, relative to the control run, averaged over the (d),(e) Ross Sea and (f),(g) West Antarctica continental shelf regions delineated in (a). Volume-averaged temperature anomalies for the final year of the experimental period are inset. When considering seasonal signals, note that the experimental period starts in May.

Under control forcing, the mean heat budget of the Antarctic continental shelf region is dominated by its role as a ventilation site for open ocean water masses with approximately 44 TW of ocean heat advected poleward across the continental shelf margin, upwelled to the surface, and released to the atmosphere. Under enhanced meltwater forcing, the transfer of heat from shelf waters to the atmosphere declines as shelf waters become increasingly stratified (Fig. 6a) and upwelling slows (Fig. 6c). Simultaneously, decreasing water-mass modification at the continental shelf margin, associated with the decline of cross-slope exchanges of cold DSW and warm CDW at DSW overflow sites (Fig. 5a) and the strengthening of density gradients inhibiting poleward cross-ASF CDW transport (Figs. 7 and 8), leads to a reduction in advective heat transport to shelf waters. Advective heat fluxes into shelf waters and surface heat fluxes out of shelf waters decline in parallel to approximately $70 \%$ (MW1.5) and 50\% (MW2.8) of their value in the control simulation, reducing the efficacy of the near-Antarctic region as a ventilation site for open ocean waters and triggering warming on the continental slope (between the 1000- and 3000-m isobaths) that persists over the experimental period (Figs. 9a-c). In contrast, the net temperature response on the continental shelf (poleward of the 1000-m isobath) is transient warming followed by cooling in both simulations (Fig. 9c). These small mean temperature trends on the shelf are the aggregate of strong regional warming and cooling signals (Figs. 9a,b). The following sections outline a detailed analysis of two localized continental shelf temperature signals of opposite sign that are robust across the MW1.5 and MW2.8 simulations; bottom intensified warming in the Ross Sea (Figs. 9d,e) and subsurface cooling in West Antarctica (Figs. 9f,g). These case studies demonstrate how the decline in DSW overturning, acceleration of geostrophic flows, and strengthening of frontal structures brought on by coastal freshening can trigger both warming and cooling on the Antarctic continental shelf.

\section{2) Ross SEA SHELF WARMING}

We conduct a heat and volume budget analysis for the Ross Sea continental shelf subdomain under control and perturbed meltwater forcing (Figs. 10a-c). In the control 
(a) Control

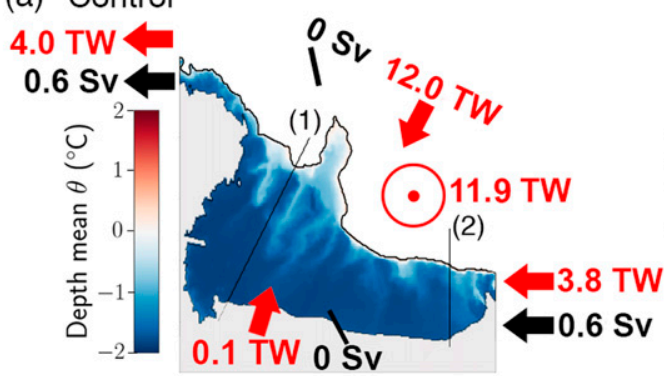

(b) MW1.5 Net: +0.9 TW

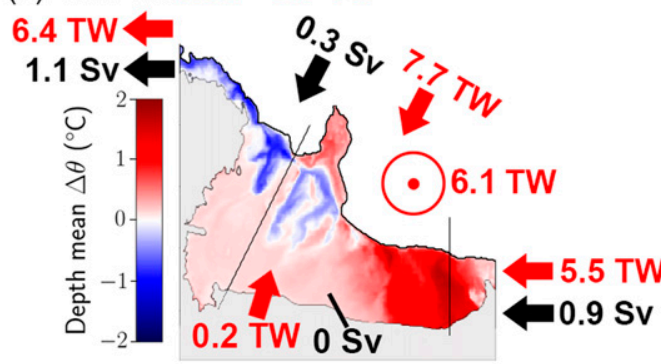

(c) MW2.8 Net: $+1.6 \mathrm{TW}$

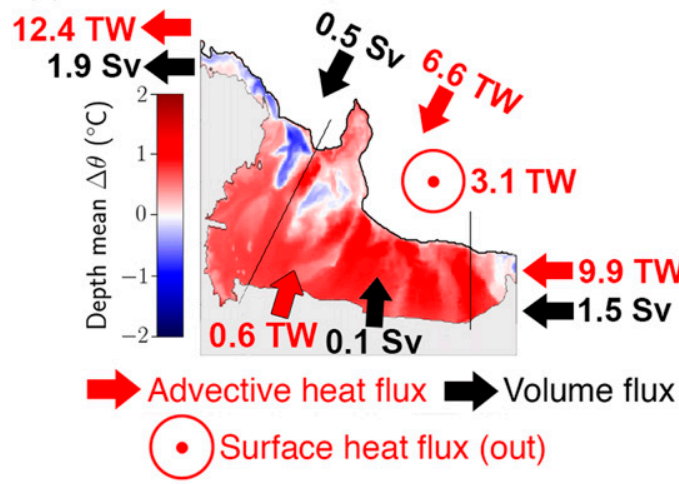

(1) West Ross Sea (Joides Trough)

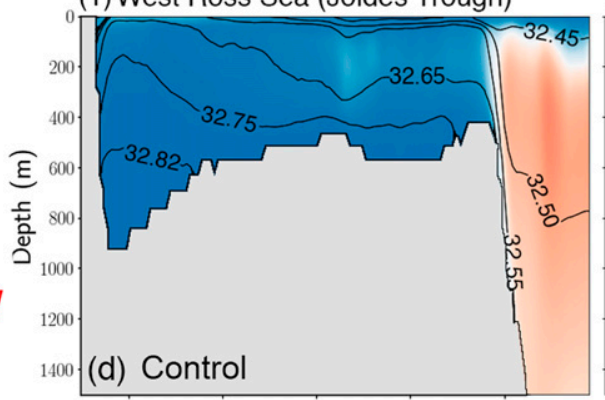

(2) East Ross Sea
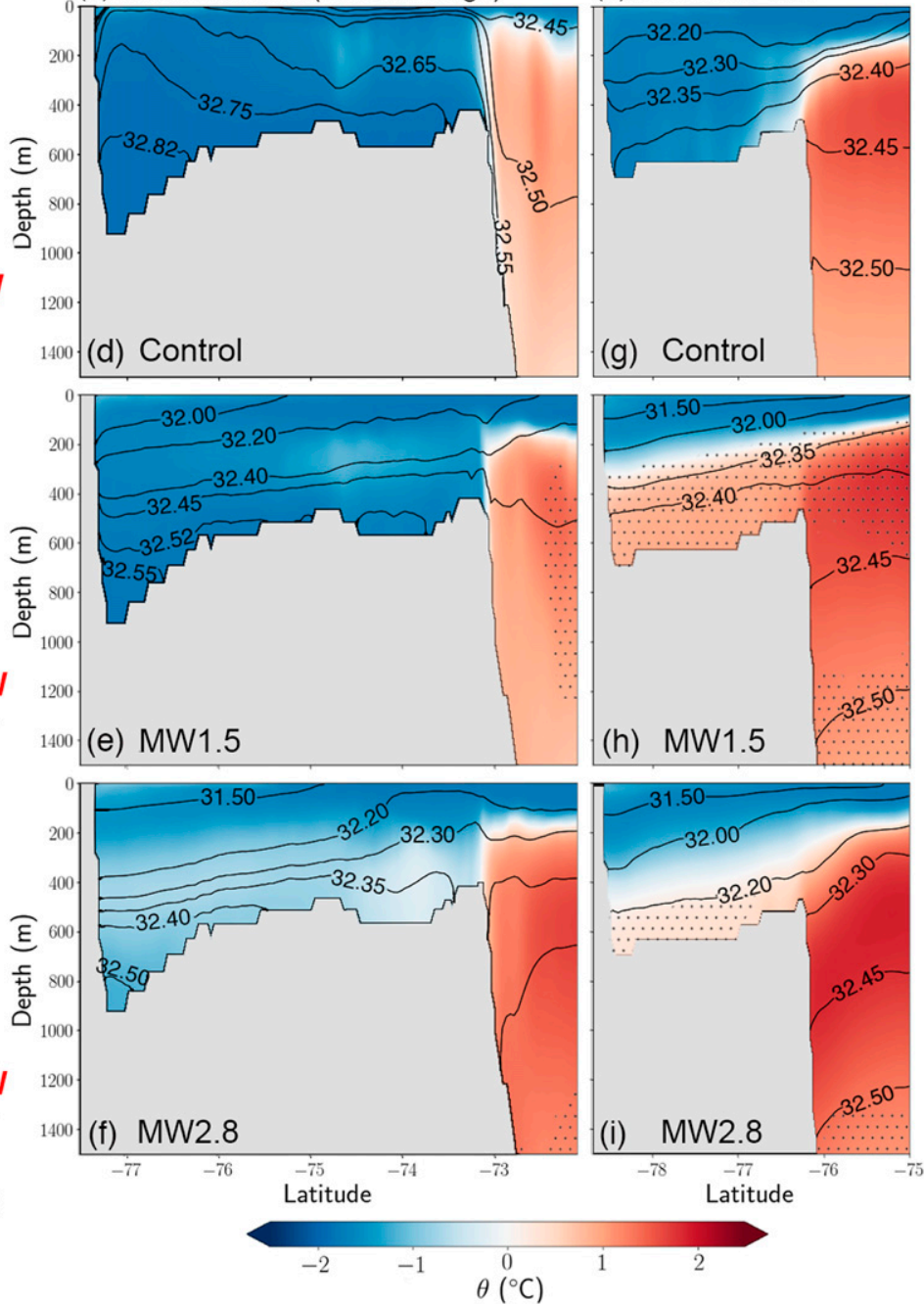

FIG. 10. Temperature response of the Ross Sea continental shelf region. (a)-(c) Time-mean advective (red arrows; TW) and surface (red circles; TW) heat flux $\left(\theta_{f}=-2.97^{\circ} \mathrm{C}\right)$ in and out of the Ross Sea region under control, MW1.5, and MW2.8 meltwater forcing, respectively. "Net" values indicate the rate of volume averaged heat gain in the region over the 10-yr perturbed simulations. Advective fluxes across the coast represent heat fluxes associated with meltwater. Shading shows depth mean temperature in (a) and temperature anomalies in (b) and (c) averaged over the final year of the experimental period. Volume fluxes to the atmosphere and sea ice field are note shown. (d)-(i) Temperature $\left(\theta\right.$; shading) and potential density $\left(\sigma_{1}\right.$; contours) along transects crossing the Joides Trough in the western Ross Sea in (d)-(f) and the Little America Basin in the eastern Ross Sea in (g)-(i), averaged over the final year of the experimental period for the three simulations. Transect locations are delineated by numbered lines in (a). Stippling in (e), (h), (f), and (l) highlights positive salinity anomalies.

simulation, the time-mean heat budget of the Ross Sea shelf is dictated by local DSW formation and export. Advective heating from the exchange of CDW and surface waters with DSW at the continental margin $(+12.0$ TW) is in near balance with surface heat losses $(-11.9$ TW), while westward coastal flows contribute a small net cooling flux ( $-0.2 \mathrm{TW})$ (Fig. 10a). Under MW1.5 freshwater forcing, surface cooling roughly halves to $-6.1 \mathrm{TW}$ as winter convection rapidly declines (Fig. 6a), and the time-mean thickness of the insulating sea ice layer increases by $9 \%$ relative to the control. The decline in surface cooling is not matched by a proportional decline in cross-isobath advective heating. Cross-isobath advective heating declines but remains elevated compared to surface cooling fluxes at $+7.7 \mathrm{TW}$ as the exchange of cold DSW and warm CDW across the continental shelf margin slows. This reduced heat flux is associated with a net onshore volume flux of $0.3 \mathrm{~Sv}$, suggesting a lag between the shutdown of DSW export and reduction of onshore CDW and surface water transport. The net warming flux of $+1.8 \mathrm{TW}$ 
introduced by this imbalance and by small heat inputs from additional meltwater is partially offset by an increase in advective cooling by westward alongshore flows to -0.9 TW, as poleward cross-isobath volume fluxes are directed into the westward coastal current. The net effect in the MW1.5 simulation is heating at a mean rate of $+0.9 \mathrm{TW}$, resulting in a volume averaged final year temperature anomaly of $+0.29^{\circ} \mathrm{C}$ driven by warming at depth (Fig. 9d). MW2.8 meltwater forcing prompts a similar, though larger, thermal response on the Ross Sea shelf. A sea ice thickness anomaly of $26 \%$, averaged over the simulation, associated with declining open water fractions (not shown) and a rapid collapse of winter convection (Fig. 6a) reduces surface cooling to $-3.1 \mathrm{TW}$. Cross-isobath advective heating remains comparatively high at $+6.6 \mathrm{TW}$ and is accompanied by a net onshore volume flux of $0.5 \mathrm{~Sv}$, while heat fluxes from meltwater flows contribute an additional +0.6 TW of warming to the region. The net thermal signal of $+4.1 \mathrm{TW}$ from shelf break processes, meltwater flows and surface cooling is moderated by an alongshore advective cooling flux of $-2.5 \mathrm{TW}$, such that the Ross Sea shelf gains heat at a rate of $+1.6 \mathrm{TW}$ over the MW2.8 simulation. This heat gain leads to a final year volume averaged temperature anomaly of $+0.51^{\circ} \mathrm{C}$.

The warming signal simulated on the Ross Sea shelf in response to coastal freshening is greater in magnitude and more consistent across the MW1.5 and MW2.8 experiments than temperature responses simulated in the Adélie Coast, Prydz Bay, and Weddell Sea (Figs. 9a,b) where DSW formation and export likewise decline (Fig. 5). We posit that convective shutdown drives subsurface warming in these DSW source regions, but that the relative magnitude of positive temperature anomalies is determined by local ASF dynamics. In the MW1.5 simulation, maximum monthly mean mixed layer depths decline rapidly on the Ross Sea shelf, reaching $57 \%$ of the control simulation in the fifth year of perturbed forcing (Fig. 6a), but remain comparatively high at $>85 \%$ of control values by the fifth year in the Adélie, Prydz, and Weddell DSW source regions (Fig. 6a). This stratification pattern is associated with a temperature signal in which only the Ross Sea DSW source region warms in response to freshening (Fig. 9a). By the 5th year of the MW2.8 experiment, however, maximum monthly mixed layer depths drop to less than $25 \%$ of control values in the Ross, Adélie, and Prydz DSW regions (Fig. 6a), and all three regions experience warming by the end of the experimental period (Fig. 9b). Maximum monthly mixed layer depths in the Weddell region, which does not warm significantly, decline to approximately $40 \%$ of control values but fully recover by the end of the MW2.8 experiment. The warming signal is visibly larger in the Ross Sea than the Adélie Coast and Prydz Bay, despite comparable mixed layer depth trends. The distinction between the Ross Sea and other DSW export regions is the absence of a strong frontal structure along the Ross Sea shelf break mediating cross-slope CDW exchange. Transects of potential temperature and density across the Joides Trough DSW overflow site in the western Ross Sea (Figs. 10d-f) reveal that isopycnal connections between CDW and shelf waters are sustained following the shutdown of DSW formation and export, supporting the interpretation of crossisobath heat and volume flux terms that modified CDW continues to access the shelf following convective shutdown. In contrast, a strong ASC interacts with DSW overflows along the Adélie Coast, Prydz Bay, and Weddell Sea shelf margins, such that shelf break isopycnal structures in these regions adopt a $\mathrm{V}$-shaped geometry when DSW is produced (see example transect from Prydz Bay in Fig. 4b), and revert to a frontal Fresh shelf regime following the shutdown of DSW convection (Fig. 4a). In the absence of a strong ASF moderating poleward CDW transport, the Ross Sea warms rapidly following stratification. This effect is most notable in the east Ross Sea where, under control forcing, lateral gradients in temperature are sustained in the absence of a strong ASF (the Cool shelf regime; see Fig. 4). In ACCESS-OM201, these cross-slope temperature gradients in the east Ross Sea are unsustainable in the absence of vigorous shelf convection. In response to MW1.5 and MW2.8 forcing, concurrent positive temperature and salinity anomalies arise at the seabed (Figs. 10g-i) as CDW floods the shelf, altering local shelf dynamics such that they resemble Warm shelf regions in West Antarctica. Persistent coastal freshening eventually acts to depress CDW isopycnals on the Ross Sea shelf (Fig. 10i) according to the mechanism outlined in section 3c, generating ASF structures that modulate shoreward heat transport and prompt a secondary cooling phase. A distinct two-stage response occurs in the MW2.8 simulation; the Ross Sea east of $172^{\circ} \mathrm{W}$ warms at a rate of $1.0 \mathrm{TW}$ in the first half of the experiment, before cooling at a rate of 0.2 TW in the second half of the experiment as strengthening fronts start to overwhelm convective shutdown.

\section{3) West ANTARCTIC SHELF COOLING}

Negative temperature anomalies simulated on the West Antarctic shelf in response to enhanced meltwater forcing (Figs. 9a,b,f,g) are driven by the establishment of frontal barriers to onshore CDW transport and the redistribution of water-mass properties around the shelf by accelerating westward geostrophic flows. Under control forcing, CDW flows poleward of the $1000 \mathrm{~m}$ isobath, unencumbered by a strong ASF, and floods the West Antarctic continental shelf (Fig. 1). A time-mean heat budget analysis of the control simulation indicates that the bulk of these waters are cooled by surface processes before flowing westward into the Ross Sea shelf, while a weaker flow transports heat eastward around the Antarctic Peninsula under the influence of the 

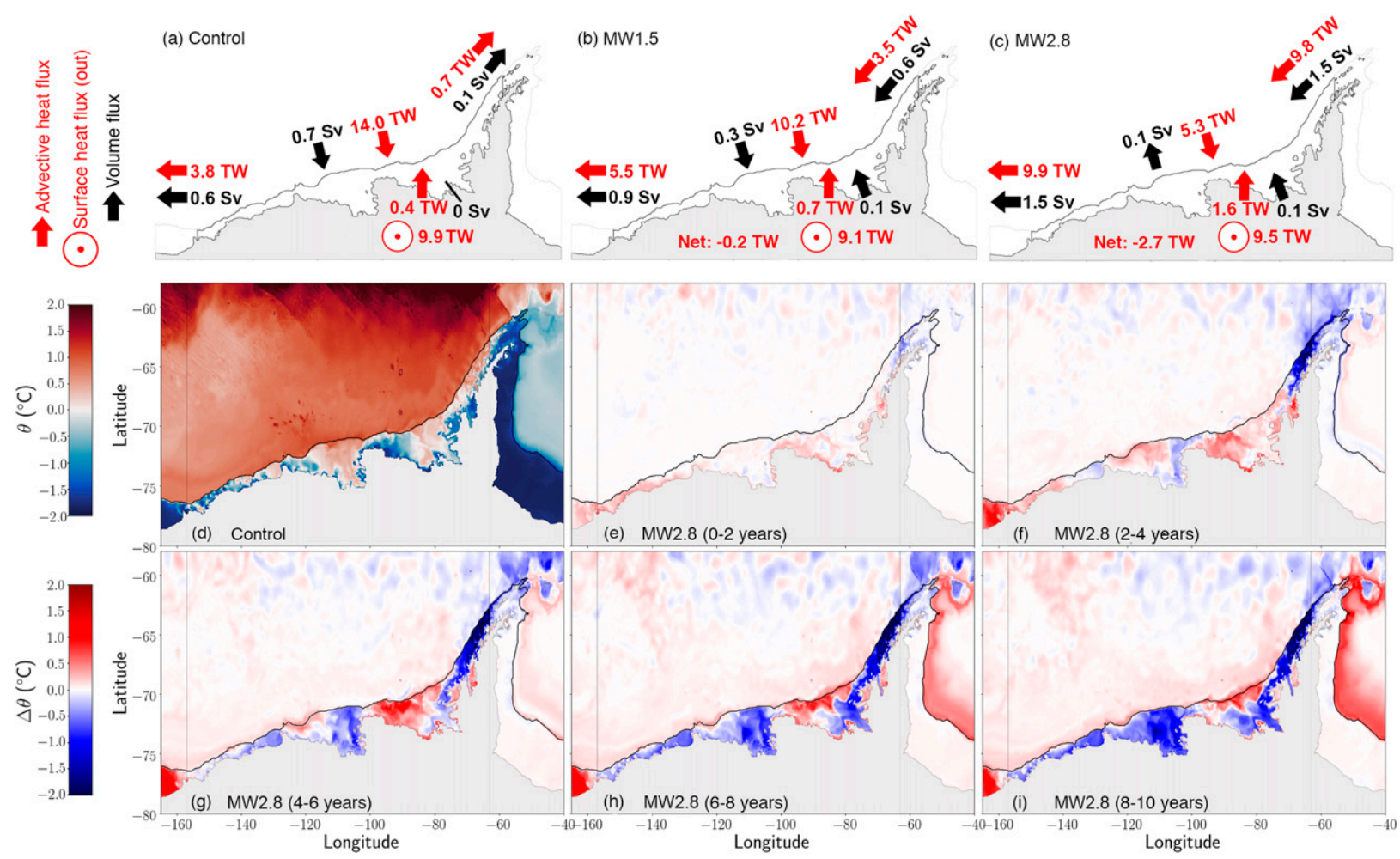

FIG. 11. Temperature response of the West Antarctic continental shelf region. (a)-(c) Time-mean advective and surface heat flux $\left(\theta_{f}=\right.$ $-2.97^{\circ} \mathrm{C}$ ) in and out of the West Antarctic shelf region under control, MW1.5, and MW2.8 meltwater forcing, respectively. "Net" values indicate the rate of volume-averaged heat gain in the region over the 10-yr perturbed simulations. Volume fluxes to the atmosphere and sea ice field are note shown. (d) Depth mean potential temperature in the West Antarctic region averaged over the 10-yr control simulation. (e)-(i) Depth mean potential temperature anomalies of the MW2.8 simulation relative to the control. Each panel shows the time averaged anomaly of a 2-yr subset of the experimental period-years $0-2,2-4,4-6,6-8$, and 8-10, respectively-in order to demonstrate the westward progression of cool anomalies with time. The final 2-yr mean depth averaged temperature anomaly of the MW1.5 simulation is nearly identical to (f) here. Black contours delineate the 1000-m isobath; gray vertical lines mark the longitudinal boundaries of the West Antarctic region considered in the heat budget analysis in (a)-(c).

ACC (Fig. 11a). Under MW1.5 and MW2.8 meltwater forcing, the direction of mean flow around the Antarctic Peninsula reverses such that the water-mass characteristics of the West Antarctic shelf become increasingly dominated by the inflow of cool Weddell Sea shelf waters as opposed to warm water from the open ocean (Figs. 11b,c). In both enhanced meltwater simulations, West Antarctic shelf waters undergo transient warming, associated with a decline in surface heat loss and the onset of heat transport into the region from its eastern boundary, followed by persistent subsurface cooling (Figs. 9f,g) that propagates westward from the Antarctic Peninsula (Figs. 11e-i). Active winter convection persists on the Weddell Sea shelf despite freshening (Fig. 6a); however, the density of these downwelling waters lessens (Fig. 6c) until they can no longer spill down the continental slope and are instead diverted into westward along-shelf flow. This redirection of flow contributes to positive temperature anomalies off the shelf in the Weddell Gyre, as open ocean waters are no longer modified by cold shelf waters, and to negative temperature anomalies on the West Antarctic shelf (Figs. 11d-i). The shelf cooling signal is accompanied by negative bottom age anomalies, as relatively old modified CDW is mixed with, and displaced by, recently ventilated Weddell Sea shelf waters (Figs. 5b,c). Accelerating flow of relatively cold, fresh Weddell Sea shelf waters along the West Antarctic depress CDW isopycnals toward the seabed (Figs. 8d,h,i), initiating westward ASC flows in previously ACC dominated regions (Fig. 7f) and, in places, shifting dominant dynamics toward a Fresh shelf regime (Fig. 4). The reduction of isopycnal pathways along which CDW can access the shelf prompts a decline in poleward cross-isobath heat transport from +14 TW in the control simulation to +10.2 TW in MW1.5 and $+5.3 \mathrm{TW}$ in MW2.8. The cooling signal associated with this decline in cross-isobath transport is only partially compensated by the warming signal associated with increasing alongshore volume fluxes. Thus, West Antarctic shelf waters lose heat at a rate of -0.2 and $-2.7 \mathrm{TW}$, averaged over 


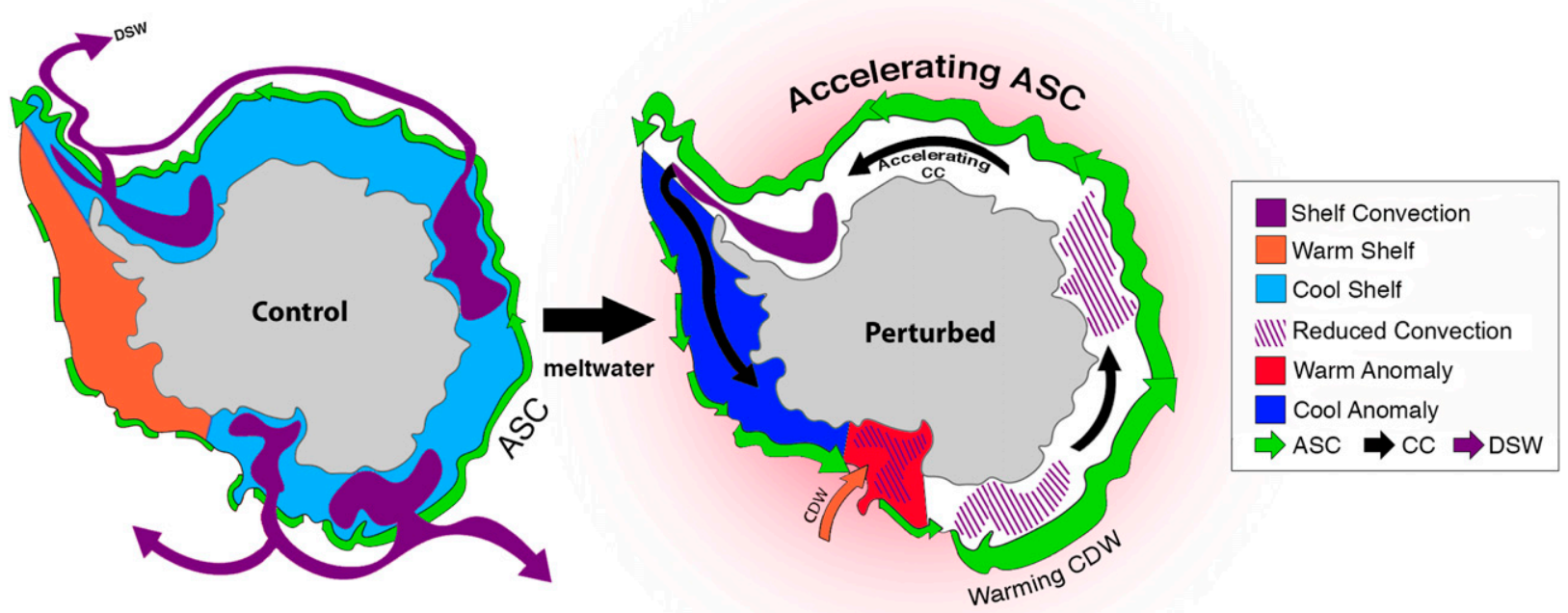

FIG. 12. Schematic of key circulation and temperature responses to meltwater, showing (left) key flow features simulated in the control simulation, and (right) responses to meltwater perturbation. Excepting reduced shelf convection in the Prydz Bay region, the illustrated responses are robust across the two forcing scenarios.

the MW1.5 and MW2.8 simulations respectively, and cool by $-0.04^{\circ}$ and $-0.53^{\circ} \mathrm{C}$, averaged over the final year of the experiments.

\section{Discussion and conclusions}

In this study, we used a $0.1^{\circ}$ resolution global oceansea ice model to investigate the response of nearAntarctic ocean circulation to freshening by glacial meltwater and to identify possible thermal feedbacks to ice-shelf melt. On the Antarctic continental shelf, freshening prompts spatially and temporally variable warming and cooling trends, indicating that enhanced meltwater input can both accelerate and inhibit ice shelf melt at different locations along the Antarctic coastline. Three meltwater-induced shifts in Antarctic shelf dynamics combine to generate this heterogeneous temperature response:

1) Stratification (warming response): Coastal freshening stratifies the water column around Antarctica, slowing upward vertical heat transfer and triggering subsurface warming.

2) Isolation (cooling response): Interaction between cool shelf waters and warm open ocean waters declines as lateral density gradients associated with the ASF strengthen and become increasingly circumpolar. Regions previously characterized by high levels of cross-slope water-mass exchange (Dense and Warm shelf regimes) transition to ASF dominated dynamics (Fresh shelf regime) that isolate shelf waters from warm CDW.
3) Homogenization (remote response): Accelerating westward coastal currents redistribute heat around the continental shelf and homogenize shelf water-mass characteristics. This mechanism generates both warming and cooling signals depending on local initial conditions relative to remote upstream water masses.

These key simulated responses are sketched in Fig. 12. In our MW1.5 and MW2.8 enhanced meltwater simulations, we find that stratification initially dominates the mean shelf temperature response before being overpowered by the isolation of shelf waters, such that shelf waters experience transient warming followed by cooling in response to freshening. Previous enhanced meltwater simulations using lower-resolution ocean models have diagnosed the subsurface warming effect of increased stratification, but have failed to resolve the shelf break dynamics that partition additional heat between the shelf and open ocean (Bronselaer et al. 2018; Fogwill et al. 2015; Golledge et al. 2019; Menviel et al. 2010; Schloesser et al. 2019). Since heat loss to the atmosphere and heat uptake from cross-slope advective transport both decline substantially over the MW1.5 and MW2.8 simulations, heat convergence due to stratification is relayed to the open ocean. This result suggests that positive feedbacks to melt incorporated into ice sheet projections may be overstated when derived from lowresolution ocean models (e.g., Golledge et al. 2019). Similar responses of heat divergence due to strengthening frontal structures and heat convergence due to increased stratification were attributed to freshening by 
precipitation in a high-resolution $\mathrm{CO}_{2}$ doubling experiment by Goddard et al. (2017), although some details were obscured by the complexity of the fully coupled system response. The complex interplay between the stratification and isolation of shelf waters highlights the importance of resolving shelf break processes when diagnosing near-Antarctic responses to forcing, while remote feedbacks generated by accelerating coastal currents stress the importance of resolving the full circumpolar domain in simulations. Our results also highlight the importance of often misrepresented DSW dynamics to the distribution of ocean heat around the shelf, as the simulated thermal response to meltwater is strongly influenced by the local presence of (e.g., Ross Sea) or downstream proximity to (e.g., West Antarctica) a DSW formation site of declining efficacy.

We focused on two regional case studies that illustrate how the three mechanisms listed above combine to produce both positive and negative temperature anomalies along the Antarctic coastline. On the Ross Sea shelf, a shutdown of winter convection (response 1) combined with the absence of a defined ASF structure modulating shoreward CDW transport (weak response 2) and the presence of comparatively warm waters upstream (response 3 ) drive warming at depth in response to MW1.5 and MW2.8 meltwater forcing [section $3 \mathrm{~d}(2)$ ]. Ross Sea shelf waters warm by an average of $0.29^{\circ}$ and $0.57^{\circ} \mathrm{C}$ following 10 years of MW1.5 and MW2.8 forcing, respectively. Due to the minor role of the ASF in the Ross Sea in ACCESS-OM2-01, the simulated warming response aligns well with expectations based on low-resolution simulations (Bronselaer et al. 2018; Fogwill et al. 2015; Golledge et al. 2019; Menviel et al. 2010; Schloesser et al. 2019) and bulk mixed-layer models (Silvano et al. 2018) that omit ASF dynamics. The sensitivity of Ross Sea shelf temperatures in ACCESS-OM2-01 agrees well with the findings of a $\mathrm{CO}_{2}$ doubling study by Goddard et al. (2017) based on $0.1^{\circ}$ resolution fully coupled climate simulations; they likewise found that a weak regional ASF lead to enhanced warming in the Ross Sea relative to other continental shelf sectors. This increasingly robust local warming response may have critical implications for sea level rise given the Ross Ice Shelf drains large portions of the West Antarctic Ice Sheet (Shepherd et al. 2018) and thermal forcing at ice shelf grounding lines has been shown to accelerate basal melt by $1 \mathrm{~m} \mathrm{yr}^{-1}$ per $0.1^{\circ} \mathrm{C}$ of ocean warming (Rignot and Jacobs 2002). By contrast, surface heat loss from West Antarctic shelf waters remains relatively stable in response to enhanced meltwater forcing (weak response 1), while accelerating coastal currents flood the West Antarctic shelf with cool, fresh Weddell Sea shelf waters (response 3). As shelf waters cool and freshen, frontal structures develop at and poleward of the shelf break, insulating ice shelves from open ocean heat (response 2). Consequentially, West Antarctic shelf waters cool by an average of $0.04^{\circ}$ and $0.53^{\circ} \mathrm{C}$ by the end of the MW1.5 and MW2.8 simulations, respectively. This is a novel result that, if robust, implies the existence of a limiting feedback to the thermal forcing of West Antarctic ice shelves currently absent from projections of West Antarctic Ice Sheet collapse (e.g., DeConto and Pollard 2016). We note, however, that the simulated cooling trend follows a transient warming signal in both experiments, suggesting that ocean temperatures adjacent to West Antarctic ice shelves may still increase in the near term in response to coastal freshening. Further, we stress that this cooling mechanism is contingent on the diversion of Weddell Sea shelf waters away from abyssal overturning into along-shelf coastal flows; therefore, this response may reduce the thermal forcing of the West Antarctic Ice Sheet at the expense of abyssal ventilation rates.

This work adds to a growing cache of simulation studies suggesting that the formation of Antarctic dense waters and corresponding abyssal overturning circulation is sensitive to the freshening of Antarctic coastal waters (see Aiken and England 2008; Fogwill et al. 2015; Kirkman and Bitz 2011; Lago and England 2019; Menviel et al. 2010; Morrison et al. 2015; Snow et al. 2016). Within the short 10 -yr experimental simulations at 2100 projected freshwater forcing, the connection between Antarctic shelf waters and abyssal circulation in ACCESS-OM2-01 collapses, suggesting that the abyssal overturning cell may experience a substantial slowdown within the coming century. Although we have focused on the response of shelf Antarctic continental shelf circulation, as abyssal conditions adjust to surface forcing at time scales that exceed our experiment duration, the slowdown of abyssal ventilation poses a pathway to abyssal warming and steric sea level rise (e.g., Lago and England 2019). A novel detail within our findings is that DSW formation is sensitive to remote freshwater forcing on the Antarctic continental shelf. In ACCESS-OM2-01, freshening by meltwater sourced primarily from West Antarctic and Ross Sea ice shelves propagates around the continent and shuts down DSW export from the Prydz Bay and Weddell Sea AABW source sites, thousands of kilometers downstream of the nearest enhanced runoff location. This result suggests that if recent trends of accelerating basal ice shelf melt in West Antarctica continue (Paolo et al. 2015; Rignot et al. 2004, 2011), shelf water-mass properties and DSW production may be impacted in remote sectors of the Antarctic continental shelf.

The results of the ACCESS-OM2-01 enhanced meltwater experiments presented here provide a unique, high-resolution, circumpolar view of the response of Antarctic circulation to coastal freshening that incorporates the effects of shifting dynamics at DSW overflow sites. However, our results carry a number of caveats. As noted in section $2 \mathrm{a}$, the $0.1^{\circ}$ horizontal 
resolution of ACCESS-OM2-01 is insufficient to fully resolve the mesoscale eddy field along the ASF. Modeling and observational studies have suggested that an eddy-driven overturning circulation may act to locally flatten isopycnals in strongly frontal ASF regions and consequently minimize the lateral density gradients CDW must traverse to access the shelf (Hattermann et al. 2014; Nøst et al. 2011). Therefore, the isopycnal steepening and reductions in cross-slope heat transport initiated by freshwater forcing in our study may be exaggerated by an underrepresentation of mesoscale processes at the shelf break. Unfortunately, the horizontal resolution required to fully characterize the mesoscale field at the Antarctic shelf break $(\sim 1 \mathrm{~km})$ remains computationally challenging for circumpolar perturbation studies. Regional simulations can be conducted at this fine resolution (e.g., Årthun et al. 2013; Graham et al. 2016; Hattermann et al. 2014; St-Laurent et al. 2013); however, our results suggest that regional meltwater perturbation experiments (e.g., Jourdain et al. 2017) omit remote feedbacks that exert a leadingorder influence over the shelf temperature response, such as interactions between Weddell Sea and West Antarctic shelf waters. We are aware of one global simulation that resolves the mesoscale eddy field at the ASF (LLC_4320; Stewart et al. 2018), but the short duration of this simulation (1 year) suggests that forcing experiments at this resolution are currently unrealistic. Future simulation studies aiming to diagnose Antarctic ocean responses to climate forcing should capture the full Southern Ocean (or global) domain and work toward an eddy-resolving grid. Representation of Antarctic continental shelf circulation and water-mass properties in ACCESS-OM2-01 is further limited by the omission of explicit tides, ice shelf cavities, and the input of glacial meltwater at depth from the model configuration. Recent simulation studies have demonstrated that tides contribute significantly to the Antarctic continental shelf heat budget (Stewart et al. 2018) and can adjust the strength and structure of the ASF and ASC (Flexas et al. 2015; Jourdain et al. 2019; Stewart et al. 2019), effects not captured in the present study. Additionally, the omission of ice shelf cavities and input of basal meltwater at the surface can lead to spuriously strong stratification of shelf waters (Mathiot et al. 2017), an effect that may exaggerate the simulated stratification response and accelerate the shutdown of DSW convection in our experiments.

We emphasize that this simulation study is not intended as a projection; instead, we have presented an idealized forcing experiment focused on interrogating the transient influence of increased melt on Antarctic waters. The 10-yr duration of our simulation is sufficient to investigate meltwater-induced changes in ocean dynamics on and near the continental shelf that set shelf conditions on short time scales; however, it is insufficient to capture adjustments in open-ocean circulation, such as shifts in Southern Ocean upwelling and ACC dynamics, that could impact shelf properties over longer periods (e.g., Morrison et al. 2015; Stouffer et al. 2007). We also note that the temporal nature of the response simulated here may be influenced by our decision to impose a stepwise forcing perturbation and should be confirmed in longer simulations where runoff rates are amplified gradually. Finally, in isolating the influence of increasing meltwater inputs on Antarctic ocean dynamics, our simulations omit feedbacks and interactions with changing surface temperatures (e.g., Goddard et al. 2017; Snow et al. 2016) or shifting westerly winds (e.g., Donat-Magnin et al. 2017; Goddard et al. 2017; Spence et al. 2014, 2017), which, together, will influence Antarctic circulation and the stability of the Antarctic Ice Sheet over the coming decades. Diagnosing interactions between the responses identified herein and other projected shifts in climate forcing is an ongoing area of research.

The future contribution of Antarctic Ice Sheet melt to global sea level rise remains highly uncertain. Observational evidence suggests that ice loss is accelerating, yet the influence of this growing freshwater flux on the climate state is poorly accounted for in climate and sea level projections. We find that coastal freshening by glacial runoff can prompt both warming and cooling at different locations around the Antarctic coast, adding nuance to the melt accelerating feedbacks that dominate the Antarctic ocean response to freshening in low-resolution models. Our results highlight the importance of representing dynamics at the shelf break and resolving the full circumpolar Antarctic domain when diagnosing feedbacks to Antarctic Ice Sheet melt. Incorporating these processes into climate models, as high-resolution ocean and ice shelf modeling tools progress, will greatly improve projections of future climate and sea level.

Acknowledgments. This research was undertaken on the National Computational Infrastructure (NCI) in Canberra, Australia, which is supported by the Australian Commonwealth Government. A.K.M. was supported by an Australian Research Council (ARC) DECRA Fellowship DE170100184. A.K.M. and A.M.H. were supported by an ARC Discovery Project DP190100494. R.M. was supported by the Australian National University A. L. Hales Honours Year Scholarship. A subset of the data used in this study will be made available at doi:10.4225/41/5a2dc8543105a. We thank the COSIMA consortium (http://cosima.org.au/) for helpful discussions and technical support, particularly Andrew E. Kiss for his work on developing and overseeing the spinup of the ACCESS-OM2-01 model configuration 
used. We also thank Nick R. Golledge for generously providing Antarctic runoff projections prior to publication. Finally, we thank Andrew L. Stewart and two anonymous reviewers for their constructive commentary on the initial manuscript.

\section{REFERENCES}

Abernathey, R. P., I. Cerovecki, P. R. Holland, E. Newsom, M. Mazloff, and L. D. Talley, 2016: Water-mass transformation by sea ice in the upper branch of the Southern Ocean overturning. Nat. Geosci., 9, 596-601, https://doi.org/10.1038/ ngeo2749.

Adcroft, A., and J.-M. Campin, 2004: Rescaled height coordinates for accurate representation of free-surface flows in ocean circulation models. Ocean Modell., 7, 269-284, https://doi.org/ 10.1016/j.ocemod.2003.09.003.

Aiken, C. M., and M. H. England, 2008: Sensitivity of the presentday climate to freshwater forcing associated with Antarctic sea ice loss. J. Climate, 21, 3936-3946, https://doi.org/10.1175/ 2007JCLI1901.1.

Årthun, M., P. R. Holland, K. W. Nicholls, and D. L. Feltham, 2013: Eddy-driven exchange between the open ocean and a sub-ice shelf cavity. J. Phys. Oceanogr., 43, 2372-2387, https:// doi.org/10.1175/JPO-D-13-0137.1.

Brambilla, E., L. D. Talley, and P. E. Robbins, 2008: Subpolar mode water in the northeastern Atlantic: 2. Origin and transformation. J. Geophys. Res., 113, C04026, https://doi.org/ 10.1029/2006JC004063.

Bronselaer, B., M. Winton, S. M. Griffies, W. J. Hurlin, K. B. Rodgers, O. V. Sergienko, R. J. Stouffer, and J. L. Russell, 2018: Change in future climate due to Antarctic meltwater. Nature, 564, 53-58, https://doi.org/10.1038/s41586-018-0712-z.

Cook, A. J., P. R. Holland, M. P. Meredith, T. Murray, A. Luckman, and D. G. Vaughan, 2016: Ocean forcing of glacier retreat in the western Antarctic Peninsula. Science, 353, 283-286, https:// doi.org/10.1126/science.aae0017.

DeConto, R. M., and D. Pollard, 2016: Contribution of Antarctica to past and future sea-level rise. Nature, 531, 591-597, https:// doi.org/10.1038/nature17145.

Depoorter, M. A., J. L. Bamber, J. A. Griggs, J. T. M. Lenaerts, S. R. M. Ligtenberg, M. R. van den Broeke, and G. Moholdt, 2013: Calving fluxes and basal melt rates of Antarctic ice shelves. Nature, 502, 89-92, https://doi.org/10.1038/nature12567.

Donat-Magnin, M., N. C. Jourdain, P. Spence, J. Le Sommer, H. Gallée, and G. Durand, 2017: Ice-shelf melt response to changing winds and glacier dynamics in the Amundsen Sea sector, Antarctica. J. Geophys. Res. Oceans, 122, $10206-$ 10 224, https://doi.org/10.1002/2017JC013059.

Flexas, M. M., M. P. Schodlok, L. Padman, D. Menemenlis, and A. H. Orsi, 2015: Role of tides on the formation of the Antarctic Slope Front at the Weddell-Scotia Confluence. J. Geophys. Res. Oceans, 120, 3658-3680, https://doi.org/ 10.1002/2014JC010372.

Fogwill, C. J., S. J. Phipps, C. S. M. Turney, and N. R. Golledge, 2015: Sensitivity of the Southern Ocean to enhanced regional Antarctic ice sheet meltwater input. Earth's Future, 3, 317329, https://doi.org/10.1002/2015EF000306.

Foster, T. D., 1995: Abyssal water mass formation off the eastern Wilkes Land coast of Antarctica. Deep-Sea Res. I, 42, 501-522, https://doi.org/10.1016/0967-0637(95)00002-N.
_ , and E. C. Carmack, 1976: Frontal zone mixing and Antarctic Bottom Water formation in the southern Weddell Sea. DeepSea Res. Oceanogr. Abstr., 23, 301-317, https://doi.org/10.1016/ 0011-7471(76)90872-X.

Fretwell, P., and Coauthors, 2013: Bedmap2: Improved ice bed, surface and thickness datasets for Antarctica. Cryosphere, $\mathbf{7}$, 375-393, https://doi.org/10.5194/tc-7-375-2013.

Goddard, P. B., C. O. Dufour, J. Yin, S. M. Griffies, and M. Winton, 2017: $\mathrm{CO}_{2}$-induced ocean warming of the Antarctic Continenta Shelf in a eddying global climate model. J. Geophys. Res. Oceans, 122, 8079-8101, https://doi.org/10.1002/2017JC012849.

Golledge, N. R., E. D. Keller, N. Gomez, K. A. Naughten, J. Bernales, L. D. Trusel, and T. L. Edwards, 2019: Global environmental consequences of twenty-first-century ice-sheet melt. Nature, $\mathbf{5 6 6}$, 65-72, https://doi.org/10.1038/s41586-019-0889-9.

Gordon, A. L., B. A. Huber, H. H. Hellmer, and A. Ffield, 1993 Deep and Bottom Water of the Weddell Sea's western rim. Science, 262, 95-97, https://doi.org/10.1126/science.262.5130.95.

—, E. Zambianchi, A. Orsi, M. Visbeck, C. F. Giulivi, T. Whitworth III, and G. Spezie, 2004: Energetic plumes over the western Ross Sea continental slope. Geophys. Res. Lett., 31, L21302, https://doi.org/10.1029/2004GL020785.

— A. H. Orsi, R. Muench, B. A. Huber, E. Zambianchi, and M. Visbeck, 2009: Western Ross Sea continental slope gravity currents. Deep-Sea Res. II, 56, 796-817, https://doi.org/10.1016/ j.dsr2.2008.10.037.

Graham, J. A., M. S. Dinniman, and J. M. Klinck, 2016: Impact of model resolution for on-shelf heat transport along the West Antarctic Peninsula. J. Geophys. Res. Oceans, 121, 7880-7897, https://doi.org/10.1002/2016JC011875.

Griffies, S. M., 2012: Elements of the Modular Ocean Model (MOM): 2012 release. GFDL Ocean Group Tech. Rep. 7, NOAA/Geophysical Fluid Dynamics Laboratory, $620 \mathrm{pp}$.

— , and Coauthors, 2009: Coordinated Ocean-ice Reference Experiments (COREs). Ocean Modell., 26, 1-46, https:// doi.org/10.1016/j.ocemod.2008.08.007.

Hattermann, T., L. Smedsrud, O. Nøst, J. Lilly, and B. Galton-Fenzi, 2014: Eddy-resolving simulations of the Fimbul Ice Shelf cavity circulation: Basal melting and exchange with open ocean. Ocean Modell., 82, 28-44, https://doi.org/10.1016/j.ocemod.2014.07.004.

Heuzé, C., K. J. Heywood, D. P. Stevens, and J. K. Ridley, 2013: Southern Ocean bottom water characteristics in CMIP5 models. Geophys. Res. Lett., 40, 1409-1414, https://doi.org/ $10.1002 / g r l .50287$.

Hunke, E. C., W. H. Lipscomb, A. K. Turner, N. Jeffery, and S. Elliott, 2015: CICE: The Los Alamos Sea Ice Model documentation and software user's manual version 5.1. Tech. Rep. LA-CC-06-012, Los Alamos National Laboratory, 116 pp.

Jacobs, S. S., 2004: Bottom water production and its links with the thermohaline circulation. Antarct. Sci., 16, 427-437, https:// doi.org/10.1017/S095410200400224X.

— , and C. F. Giulivi, 2010: Large multidecadal salinity trends near the Pacific-Antarctic continental margin. J. Climate, $\mathbf{2 3}$ 4508-4524, https://doi.org/10.1175/2010JCLI3284.1.

_ A. F. Amos, and P. M. Bruchhausen, 1970: Ross Sea oceanography and Antarctic Bottom Water formation. Deep-Sea Res. Oceanogr. Abstr., 17, 935-962, https://doi.org/10.1016/ 0011-7471(70)90046-X.

Jenkins, A., P. Dutrieux, S. Jacobs, E. J. Steig, G. H. Gudmundsson, J. Smith, and K. J. Heywood, 2016: Decadal ocean forcing and Antarctic ice sheet response: Lessons from the Amundsen Sea. Oceanography, 29, 106-117, https://doi.org/10.5670/oceanog.2016.103. 
—, D. Shoosmith, P. Dutrieux, S. Jacobs, T. W. Kwan, S. H. Lee, H. K. Ha, and S. Stammerjohn, 2018: West Antarctic Ice Sheet retreat in the Amundsen Sea driven by decadal oceanic variability. Nat. Geosci., 11, 733-738, https://doi.org/10.1038/s41561018-0207-4.

Johnson, G. C., 2008: Quantifying Antarctic Bottom Water and North Atlantic Deep Water volumes. J. Geophys. Res., 113, C05027, https://doi.org/10.1029/2007JC004477.

Jourdain, N. C., P. Mathiot, N. Merino, G. Durand, J. Le Sommer, P. Spence, P. Dutrieux, and G. Madec, 2017: Ocean circulation and sea-ice thinning induced by melting ice shelves in the Amundsen Sea. J. Geophys. Res. Oceans, 122, 2550-2573, https://doi.org/10.1002/2016JC012509.

— J.-M. Molines, J. L. Sommer, P. Mathiot, J. Chanut, C. de Lavergne, and G. Madec, 2019: Simulating or prescribing the influence of tides on the Amundsen Sea ice shelves. Ocean Modell., 133, 44-55, https://doi.org/10.1016/j.ocemod.2018.11.001.

Kirkman, C. H., and C. M. Bitz, 2011: The effect of the sea ice freshwater flux on Southern Ocean temperatures in CCSM3: Deep-ocean warming and delayed surface warming. J. Climate, 24, 2224-2237, https://doi.org/10.1175/2010JCLI3625.1.

Kiss, A. E., and Coauthors, 2019: ACCESS-OM2 v1.0: A global ocean-sea ice model at three resolutions. Geosci. Model Dev., 13, 401-442, https://doi.org/10.5194/GMD-13-401-2020.

Lago, V., and M. H. England, 2019: Projected slowdown of Antarctic Bottom Water formation in response to amplified meltwater contributions. J. Climate, 32, 6319-6335, https:// doi.org/10.1175/JCLI-D-18-0622.1.

Locarnini, R. A., and Coauthors, 2013: Temperature. Vol. 1, World Ocean Atlas 2013, NOAA Atlas NESDIS 73, 40 pp., http:// data.nodc.noaa.gov/woa/WOA13/DOC/woa13_vol1.pdf.

Martin, T., and A. Adcroft, 2010: Parameterizing the fresh-water flux from land ice to ocean with interactive icebergs in a coupled climate model. Ocean Modell., 34, 111-124, https:// doi.org/10.1016/j.ocemod.2010.05.001.

Mathiot, P., A. Jenkins, C. Harris, and G. Madec, 2017: Explicit representation and parametrised impacts of under ice shelf seas in the $z^{*}$ coordinate ocean model NEMO 3.6. Geosci. Model Dev., 10, 2849-2874, https://doi.org/10.5194/gmd-10-2849-2017.

Menviel, L., A. Timmermann, O. E. Timm, and A. Mouchet, 2010: Climate and biogeochemical response to a rapid melting of the West Antarctic Ice Sheet during interglacials and implications for future climate. Paleoceanography, 25, PA4231, https:// doi.org/10.1029/2009PA001892.

Moffat, C., and M. Meredith, 2018: Shelf-ocean exchange and hydrography west of the Antarctic Peninsula: A review. Philos. Trans. Roy. Soc., 376A, 20170164, https://doi.org/ 10.1098/RSTA.2017.0164.

Morlighem, M., and Coauthors, 2019: Deep glacial troughs and stabilizing ridges unveiled beneath the margins of the Antarctic ice sheet. Nat. Geosci., 13, 132-137, https://doi.org/10.1038/ s41561-019-0510-8.

Morrison, A. K., M. H. England, and A. M. Hogg, 2015: Response of Southern Ocean convection and abyssal overturning to surface buoyancy perturbations. J. Climate, 28, 4263-4278, https://doi.org/10.1175/JCLI-D-14-00110.1.

—, A. M. Hogg, M. H. England, and P. Spence, 2020: Warm Circumpolar Deep Water transport toward Antarctica driven by local dense water export in canyons. $S c i$. $A d v$., 6, eaav2516, https://doi.org/10.1126/sciadv.aav2516.

Nakayama, Y., R. Timmermann, M. Schröder, and H. Hellmer, 2014: On the difficulty of modeling Circumpolar Deep Water intru- sions onto the Amundsen Sea continental shelf. Ocean Modell., 84, 26-34, https://doi.org/10.1016/j.ocemod.2014.09.007.

Newsom, E. R., C. M. Bitz, F. O. Bryan, R. Abernathey, and P. R. Gent, 2016: Southern Ocean deep circulation and heat uptake in a high-resolution climate model. J. Climate, 29, 2597-2619, https://doi.org/10.1175/JCLI-D-15-0513.1.

Nøst, O. A., M. Biuw, V. Tverberg, C. Lydersen, T. Hattermann, Q. Zhou, L. H. Smedsrud, and K. M. Kovacs, 2011: Eddy overturning of the Antarctic Slope Front controls glacial melting in the eastern Weddell Sea. J. Geophys. Res., 116, C11014, https://doi.org/10.1029/2011JC006965.

Ohshima, K. I., and Coauthors, 2013: Antarctic Bottom Water production by intense sea-ice formation in the Cape Darnley polynya. Nat. Geosci., 6, 235-240, https://doi.org/10.1038/ ngeo1738.

Orsi, A. H., G. C. Johnson, and J. L. Bullister, 1999: Circulation, mixing, and production of Antarctic Bottom Water. Prog. Oceanogr., 43, 55-109, https://doi.org/10.1016/S0079-6611(99) 00004-X.

— W. M. Smethie, and J. L. Bullister, 2002: On the total input of Antarctic waters to the deep ocean: A preliminary estimate from chlorofluorocarbon measurements. J. Geophys. Res., 107, 3122, https://doi.org/10.1029/2001JC000976.

Paolo, F. S., H. A. Fricker, and L. Padman, 2015: Volume loss from Antarctic ice shelves is accelerating. Science, 348, 327-331, https://doi.org/10.1126/science.aaa0940.

Pellichero, V., J.-B. Sallée, C. C. Chapman, and S. M. Downes, 2018: The Southern Ocean meridional overturning in the seaice sector is driven by freshwater fluxes. Nat. Commun., 9, 1789, https://doi.org/10.1038/s41467-018-04101-2.

Purkey, S. G., and G. C. Johnson, 2010: Warming of global abyssal and deep Southern Ocean waters between the 1990s and 2000s: Contributions to global heat and sea level rise budgets. J. Climate, 23, 6336-6351, https://doi.org/10.1175/2010JCLI3682.1.

—, and —, 2012: Global contraction of Antarctic Bottom Water between the 1980s and 2000s. J. Climate, 25, 5830-5844, https://doi.org/10.1175/JCLI-D-11-00612.1.

$\longrightarrow$, and - 2013: Antarctic bottom water warming and freshening: Contributions to sea level rise, ocean freshwater budgets, and global heat gain. J. Climate, 26, 6105-6122, https:// doi.org/10.1175/JCLI-D-12-00834.1.

Rignot, E., and S. S. Jacobs, 2002: Rapid bottom melting widespread near Antarctic Ice Sheet grounding lines. Science, 296, 2020-2023, https://doi.org/10.1126/science.1070942.

_ G. Casassa, P. Gogineni, W. Krabill, A. Rivera, and R. Thomas, 2004: Accelerated ice discharge from the Antarctic Peninsula following the collapse of Larsen B ice shelf. Geophys. Res. Lett., 31, L18401, https://doi.org/10.1029/2004GL020697.

_, I. Velicogna, M. R. van den Broeke, A. Monaghan, and J. T. M. Lenaerts, 2011: Acceleration of the contribution of the Greenland and Antarctic Ice Sheets to sea level rise. Geophys. Res. Lett., 38, L05503, https://doi.org/10.1029/2011GL046583.

Schloesser, F., T. Friedrich, A. Timmermann, R. M. DeConto, and D. Pollard, 2019: Antarctic iceberg impacts on future Southern Hemisphere climate. Nat. Climate Change, 9, 672-677, https:// doi.org/10.1038/s41558-019-0546-1.

Schmidtko, S., K. J. Heywood, A. F. Thompson, and S. Aoki, 2014: Multidecadal warming of Antarctic waters. Science, 346, 12271231, https://doi.org/10.1126/science.1256117.

Shepherd, A., and Coauthors, 2018: Mass balance of the Antarctic Ice Sheet from 1992 to 2017. Nature, 556, 219-222, https:// doi.org/10.1038/s41586-018-0179-y. 
Silvano, A., S. Rintoul, B. Peña-Molino, W. Hobbs, E. Van Wijk, S. Aoki, T. Tamura, and G. Williams, 2018: Freshening by glacial meltwater enhances melting of ice shelves and reduces formation of Antarctic Bottom Water. Sci. Adv., 4 eaap9467, https://doi.org/10.1126/sciadv.aap9467.

Smith, G. C., and Coauthors, 2019: Polar ocean observations: A critical gap in the observing system and its effect on environmental predictions from hours to a season. Front. Mar. Sci., 6, 429, https://doi.org/10.3389/fmars.2019.00429.

Snow, K., A. M. Hogg, B. M. Sloyan, and S. M. Downes, 2016: Sensitivity of Antarctic Bottom Water to changes in surface buoyancy fluxes. J. Climate, 29, 313-330, https://doi.org/ 10.1175/JCLI-D-15-0467.1.

Spence, P., S. M. Griffies, M. H. England, A. M. Hogg, O. A. Saenko, and N. C. Jourdain, 2014: Rapid subsurface warming and circulation changes of Antarctic coastal waters by poleward shifting winds. Geophys. Res. Lett., 41, 4601-4610, https://doi.org/10.1002/2014GL060613.

, R. M. Holmes, A. M. Hogg, S. M. Griffies, K. D. Stewart, and M. H. England, 2017: Localized rapid warming of West Antarctic subsurface waters by remote winds. Nat. Climate Change, 7, 595-603, https://doi.org/10.1038/nclimate3335.

Stacey, M. W., S. Pond, and Z. P. Nowak, 1995: A numerical model of the circulation in Knight Inlet, British Columbia, Canada. J. Phys. Oceanogr., 25, 1037-1062, https://doi.org/10.1175/ 1520-0485(1995)025<1037:ANMOTC >2.0.CO;2.

Stewart, A. L., and A. F. Thompson, 2015: Eddy-mediated transport of warm Circumpolar Deep Water across the Antarctic Shelf Break. Geophys. Res. Lett., 42, 432-440, https://doi.org/ 10.1002/2014GL062281.

- and _ 2016: Eddy generation and jet formation via dense water outflows across the Antarctic Continental Slope. J. Phys. Oceanogr., 46, 3729-3750, https://doi.org/10.1175/JPO-D-160145.1.
— A. Klocker, and D. Menemenlis, 2018: Circum-Antarctic shoreward heat transport derived from an eddy- and tideresolving simulation. Geophys. Res. Lett., 45, 834-845, https:// doi.org/10.1002/2017GL075677.

,-- , and - 2019: Acceleration and overturning of the Antarctic Slope Current by winds, eddies, and tides. J. Phys. Oceanogr., 49, 2043-2074, https://doi.org/10.1175/JPO-D-18-0221.1.

Stewart, K., and Coauthors, 2020: JRA55-do-based repeat year forcing datasets for driving ocean-sea-ice models. Ocean Modell., 147, 101557, https://doi.org/10.1016/j.ocemod.2019.101557.

St-Laurent, P., J. M. Klinck, and M. S. Dinniman, 2013: On the role of coastal troughs in the circulation of warm circumpolar deep water on Antarctic shelves. J. Phys. Oceanogr., 43, 51-64, https://doi.org/10.1175/JPO-D-11-0237.1.

Stouffer, R. J., D. Seidov, and B. J. Haupt, 2007: Climate response to external sources of freshwater: North Atlantic versus the Southern Ocean. J. Climate, 20, 436-448, https://doi.org/ 10.1175/JCLI4015.1.

Swingedouw, D., T. Fichefet, H. Goosse, and M. F. Loutre, 2009: Impact of transient freshwater releases in the Southern Ocean on the AMOC and climate. Climate Dyn., 33, 365-381, https:// doi.org/10.1007/s00382-008-0496-1.

Thompson, A. F., A. L. Stewart, P. Spence, and K. J. Heywood, 2018: The Antarctic Slope Current in a changing climate. Rev. Geophys., 56, 741-770, https://doi.org/10.1029/2018RG000624.

Tsujino, H., and Coauthors, 2018: JRA-55 based surface dataset for driving ocean-sea-ice models (JRA55-do). Ocean Modell., 130, 79-139, https://doi.org/10.1016/j.ocemod.2018.07.002.

Williams, G. D., N. L. Bindoff, S. J. Marsland, and S. R. Rintoul, 2008: Formation and export of dense shelf water from the Adélie Depression, East Antarctica. J. Geophys. Res., 113, C04039, https://doi.org/10.1029/2007JC004346.

Zweng, M., and Coauthors, 2013: Salinity. Vol. 2, World Ocean Atlas 2013, NOAA Atlas NESDIS 74, 39 pp., http://data.nodc.noaa.gov/ woa/WOA13/DOC/woa13_vol2.pdf. 